NBER WORKING PAPER SERIES

\title{
UNDERSTANDING THE EFFECTS OF GOVERNMENT SPENDING ON CONSUMPTION
}

\author{
Jordi Galí \\ J. David López-Salido \\ Javier Vallés \\ Working Paper 11578 \\ http://www.nber.org/papers/w11578
NATIONAL BUREAU OF ECONOMIC RESEARCH
1050 Massachusetts Avenue
Cambridge, MA 02138
August 2005

\begin{abstract}
We wish to thank Alberto Alesina, Javier Andrés, Florin Bilbiie, Günter Coenen, Gabriel Fagan,Eric Leeper, Ilian Mihov, Valery Ramey, Michael Reiter, Jaume Ventura, Lutz Weinke, co-editor Roberto Perotti, two anonymous referees, and seminar participants at the Bank of Spain, Bank of England, CREI-UPF, IGIER-Bocconi, INSEAD, York, Salamanca, NBER Summer Institute 2002, the 1st Workshop on Dynamic Macroeconomics at Hydra, the EEA Meetings in Stockholm and the 2nd International Research Forum on Monetary Policy for useful comments and suggestions. Galí acknowledges the Pnancial support and hospitality of the Banco de España, and CREA-Barcelona Economics for research support. Anton Nakov provided excellent research assistance. This paper was written while the last author was working at the Research Department of the Banco de España. The opinions and analyses are the responsability of the authors and, therefore, do not necessarily coincide with those of the Banco de España or the Eurosystem. The views expressed herein are those of the author(s) and do not necessarily reflect the views of the National Bureau of Economic Research.
\end{abstract}

C2005 by Jordi Galí, J. David López-Salido and Javier Vallés. All rights reserved. Short sections of text, not to exceed two paragraphs, may be quoted without explicit permission provided that full credit, including (C) notice, is given to the source. 
Understanding the Effects of Government Spending on Consumption

Jordi Galí, J. David López-Salido and Javier Vallés

NBER Working Paper No. 11578

August 2005

JEL No. E32, E62

\title{
$\underline{\text { ABSTRACT }}$
}

Recent evidence suggests that consumption rises in response to an increase in government spending. That finding cannot be easily reconciled with existing optimizing business cycle models. We extend the standard new Keynesian model to allow for the presence of rule-of-thumb consumers. We show how the interaction of the latter with sticky prices and deficit financing can account for the existing evidence on the effects of government spending.

\author{
Jordi Galí \\ MIT Department of Economics \\ 50 Memorial Drive E52-359 \\ Cambridge, MA 02142 \\ and NBER \\ jgali@upf.edu \\ J. David López-Salido \\ Banco de España \\ Alcala 48 \\ 28014 Madrid \\ SPAIN \\ davidl@bde.es \\ Javier Vallés \\ Oficina Económica \\ Presidencia del Gobierno \\ 28071 Madrid \\ SPAIN \\ jvalles@presidencia.gob.es
}




\section{Introduction}

What are the effects of changes in government purchases on aggregate economic activity? How are those effects transmitted? Even though such questions are central to macroeconomics and its ability to inform economic policy, there is no widespread agreement on their answer. In particular, though most macroeconomic models predict that a rise in government purchases will have an expansionary effect on output, those models often differ regarding the implied effects on consumption. Since the latter variable is the largest component of aggregate demand, its response is a key determinant of the size of the government spending multiplier.

The standard RBC and the textbook IS-LM models provide a stark example of such differential qualitative predictions. The standard RBC model generally predicts a decline in consumption in response to a rise in government purchases of goods and services (henceforth, government spending, for short). In contrast, the IS-LM model predicts that consumption should rise, hence amplifying the effects of the expansion in government spending on output. Of course, the reason for the differential impact across those two models lies in how consumers are assumed to behave in each case. The RBC model features infinitely-lived Ricardian households, whose consumption decisions at any point in time are based on an intertemporal budget constraint. Ceteris paribus, an increase in government spending lowers the present value of after-tax income, thus generating a negative wealth effect that induces a cut in consumption. ${ }^{1}$ By way of contrast, in the IS-LM model consumers behave in a non-Ricardian fashion, with their consumption being a function of their current disposable income and not of their lifetime resources. Accordingly, the implied effect

\footnotetext{
${ }^{1}$ The mechanisms underlying those effects are described in detail in Aiyagari et al. (1990), Baxter and King (1993), Christiano and Eichenbaum (1992), and Fatás and Mihov (2001), among others. In a nutshell, an increase in (non-productive) government purchases, financed by current or future lump-sum taxes, has a negative wealth effect which is reflected in lower consumption. It also induces a rise in the quantity of labor supplied at any given wage. The latter effect leads, in equilibrium, to a lower real wage, higher employment and higher output. The increase in employment leads, if sufficiently persistent, to a rise in the expected return to capital, and may trigger a rise in investment. In the latter case the size of the multiplier is greater or less than one, depending on parameter values.
} 
of an increase in government spending will depend critically on how the latter is financed, with the multiplier increasing with the extent of deficit financing. ${ }^{2}$

What does the existing empirical evidence have to say regarding the consumption effects of changes in government spending? Can it help discriminate between the two paradigms mentioned above, on the grounds of the observed response of consumption? A number of recent empirical papers shed some light on those questions. They all apply multivariate time series methods in order to estimate the responses of consumption and a number of other variables to an exogenous increase in government spending. They differ, however, on the assumptions made in order to identify the exogenous component of that variable. In Section 2 we describe in some detail the findings from that literature that are most relevant to our purposes, and provide some additional empirical results of our own. In particular, and like several other authors that preceded us, we find that a positive government spending shock leads to a significant increase in consumption, while investment either falls or does not respond significantly. Thus, our evidence seems to be consistent with the predictions of models with non-Ricardian consumers, and hard to reconcile with those of the neoclassical paradigm.

After reviewing the evidence, we turn to our paper's main contribution: the development of a simple dynamic general equilibrium model that can potentially account for that evidence. Our framework shares many ingredients with recent dynamic optimizing sticky price models, though we modify the latter by allowing for the presence of rule-of-thumb behavior by some households. ${ }^{3}$ Following Campbell and Mankiw

\footnotetext{
${ }^{2}$ See, e.g., Blanchard (2001). The total effect on output will also depend on the investment response. Under the assumption of a constant money supply, generally maintained in textbook versions of that model, the rise in consumption is accompanied by an investment decline (resulting from a higher interest rate). If instead the central bank holds the interest rate steady in the face of the increase in government spending, the implied effect on investment is nil. However, any "intermediate" response of the central bank (i.e., one that does not imply full accommodation of the higher money demand induced by the rise in output) will also induce a fall in investment in the IS-LM model.

${ }^{3}$ See, e.g., Rotemberg and Woodford (1999), Clarida, Gali and Gertler (1999), or Woodford (2003) for a description of the standard new Keynesian model.
} 
(1989), we assume that rule-of-thumb consumers do not borrow or save; instead, they are assumed to consume their current income fully. In our model, rule-of-thumb consumers coexist with conventional infinite-horizon Ricardian consumers.

The introduction of rule-of-thumb consumers in our model is motivated by an extensive empirical literature pointing to substantial deviations from the permanent income hypothesis. Much of that literature provides evidence of "excessive" dependence of consumption on current income. That evidence is based on the analysis of aggregate time series ${ }^{4}$, as well as natural experiments using micro data (e.g. response to anticipated tax refunds). ${ }^{5}$ That evidence also seems consistent with the observation that a significant fraction of households have near-zero net worth. ${ }^{6}$ On the basis of that evidence, Mankiw (2000) calls for the systematic incorporation of non-Ricardian households in macroeconomic models, and for an examination of the policy implications of their presence.

As further explained below, the existence of non-Ricardian households cannot in itself generate a positive response of consumption to a rise in government spending. To see this, consider the following equilibrium condition

$$
m p n_{t}=\mu_{t}+c_{t}+\varphi n_{t}
$$

where $m p n_{t}, c_{t}$, and $n_{t}$ represent the (logs) of the marginal product of labor, consumption, and hours worked, respectively. The term $c_{t}+\varphi n_{t}$ represents the (log) marginal rate of substitution, with parameter $\varphi>0$ measuring the curvature of the marginal disutility of labor. Variable $\mu_{t}$ is thus the wedge between the marginal rate of substitution and the marginal product of labor, and can be interpreted as the sum of both the (log) wage and price markups, as discussed in Galí, Gertler, and López-Salido (2005).

Consider first an economy with a constant wedge, $\mu_{t}=\mu$ for all $t$. Notice that

\footnotetext{
${ }^{4}$ See, e.g. Campbell and Mankiw (1989), Deaton (1992) and references therein.

${ }^{5}$ See, e.g., Souleles (1999), and Johnson, Parker and Souleles (2004).

${ }^{6}$ See, e.g., Wolff (1998)
} 
the particular case of $\mu=0$ corresponds to the perfectly competitive case often assumed in the RBC literature. According to both theory and evidence, an increase in government purchases raises hours and, under standard assumptions, lowers the marginal product of labor. Thus, it follows that consumption must drop if the previous condition is to be satisfied. Hence, a necessary condition for consumption to rise in response to a fiscal expansion is the existence of a simultaneous decline in the wedge $\mu_{t}$. This motivates the introduction in our framework of the assumption of sticky prices in goods markets (and, at least in one version of our model, of imperfectly competitive labor markets), complementing the presence of non-Ricardian consumers. As described below, our model predicts responses of aggregate consumption and other variables that are in line with the existing evidence, given plausible calibrations of the fraction of rule-of-thumb consumers, the degree of price stickiness, and the extent of deficit financing, .

Beyond the narrower focus of the present paper, a simple lesson emerges from our analysis: allowing for deviations from the strict Ricardian behavior assumed in the majority of existing macro models may be required in order to capture important aspects of the economy's workings. ${ }^{7}$ Our proposed framework, based on the simple model of rule-of-thumb consumers of Campbell and Mankiw (1989), while admittedly ad-hoc, provides in our view a good starting point.

The rest of the paper is organized as follows. Section 2 describes the existing empirical literature and provides some new evidence. Section 3 lays out the model and its different blocks. Section 4 contains an analysis of the model's equilibrium dynamics. Section 5 examines the equilibrium response to a government spending shock under alternative calibrations, focusing on the response of consumption and its consistency with the existing evidence. Section 6 summarizes the main findings of the paper and points to potential extensions and directions for further research.

\footnotetext{
${ }^{7}$ In a companion paper (Galí, López-Salido and Vallés (2005)), we study the implications of rule-of-thumb consumers for the stability properties of Taylor-type rules.
} 


\section{An Overview of the Evidence}

In the present section we start by summarizing the existing evidence on the response of consumption (and some other variables) to an exogenous increase in government spending, and provide some new evidence of our own. Most of the existing evidence relies on structural vector autoregressive models, with different papers using alternative identification schemes. Unfortunately, the data does not seem to speak with a single voice on this issue: while some papers uncover a large, positive and significant response of consumption, others find that such a response is small and often insignificant. As far as we know, however, there is no evidence in the literature pointing to the large and significant negative consumption response that would be consistent with the predictions of the neoclassical model.

Blanchard and Perotti (2002) and Fatás and Mihov (2001) identify exogenous shocks to government spending by assuming that the latter variable is predetermined relative to the other variables included in the VAR. Their most relevant findings for our purposes can be summarized as follows. First, a positive shock to government spending leads to a persistent rise in that variable. Second, the implied fiscal expansion generates a positive response in output, with the associated multiplier being greater than one in Fatás and Mihov (2001), but close to one in Blanchard and Perotti (2002). Third, in both papers the fiscal expansion leads to large (and significant) increases in consumption. Fourth, the response of investment to the spending shock is found to be insignificant in Fatás and Mihov (2001), but negative (and significant) in Blanchard and Perotti (2002).

Here we provide some complementary evidence using an identification strategy similar to the above mentioned papers. Using U.S. quarterly data, we estimate the responses of several macroeconomic variables to a government spending shock. The latter is identified by assuming that government purchases are not affected contemporaneously (i.e. within the quarter) by the innovations in the other variables contained 
in a VAR..$^{8}$ Our VAR includes a measure of government spending, GDP, hours worked, consumption of nondurables and services, private nonresidential investment, the real wage, the budget deficit, and personal disposable income. In a way consistent with the model developed below, both government spending and the budget deficit enter the VAR as a ratio to trend GDP, where the latter is proxied by (lagged) potential output. The remaining variables are specified in logs, following convention. ${ }^{9}$.

Figure 1 displays the estimated impulse responses. Total government spending rises significantly and persistently, with a half-life of about four years. Output rises persistently in response to that shock, as predicted by the theory. Most interestingly, however, consumption is also shown to rise on impact and to remain persistently above zero. A similar pattern is displayed by disposable income; in fact, as shown in the bottom right graph, the response of consumption tracks, almost one-for-one, that of disposable income. With respect to the labor variables, our point estimates imply that both hours and the real wage rise persistently in response to the fiscal shock, although with some delay relative to government spending itself. ${ }^{10}$ By contrast investment falls slightly in the short run, though the response is not significant. Finally, the deficit

\footnotetext{
${ }^{8}$ Qualitatively, the results below are robust to the use of military spending (instead of total government purchases) as a predetermined variable in the VAR, as in Rotemberg and Woodford (1992).

${ }^{9}$ We use quarterly U.S. data over the period 1954:I-2003:IV. The series were drawn from Estima's USECON database (mnemonics reported in brackets below). These include government (Federal + State + Local) consumption and gross investment expenditures (GH), gross domestic product $(\mathrm{GDPH})$, a measure of aggregate hours obtained by multiplying total civilian employment (LE) by weekly average hours in manufacturing (LRMANUA), nonfarm business hours (LXNFH), the real compensation per hour in the nonfarm business sector (LXNFR), consumption of nondurable and services $(\mathrm{CNH}+\mathrm{CSH})$, non-residential investment $(\mathrm{FNH})$, and the $\mathrm{CBO}$ estimate of potential GDP (GDPPOTHQ). All quantity variables are in log levels, and normalized by the size of the civilian population over 16 years old (LNN). We included four lags of each variable in the VAR. Our deficit measure corresponds to gross government investment (GFDI+GFNI+GSI) minus gross government savings (obtained from the FRED-II database). The resulting variable, expressed in nominal terms was normalized by the lagged trend nominal GDP (GDPPOTQ). Finally, disposable income corresponds to real personal disposable income, also drawn from the FRED-II.

${ }^{10}$ Fatas and Mihov (2001) also uncover a significant rise in the real wage in response to a spending shock, using compensation per hour in the non-farm business sector as a measure of the real wage. The positive comovement between hours and the real wage in response to a shock in military spending was originally emphasized by Rotemberg and Woodford (1992). See also Rotemberg and Woodford (1995).
} 
rises significantly on impact, remaining positive for about two years.

Our point estimates in Figure 1 imply a government spending multiplier on output, $\frac{d Y_{t+k}}{d G_{t}}$, of 0.78 on impact $(k=0)$, and of 1.74 at the end of the second year $(k=8)$. Such estimated multipliers are of a magnitude similar to the ones reported by Blanchard and Perotti (2002). They are also roughly consistent with the range of estimated short-run expenditure multipliers generated by a variety of macroeconometric models. ${ }^{11}$ Most importantly for our purposes is the observation that the multiplier on consumption is always positive, going from 0.17 on impact to 0.95 at the end of the second year.

Table 1 illustrates the robustness of these findings to alternative specifications of the VAR, including number of variables (four vs. eight variable), sample period (full postwar, post Korean war, and post-1960), and definition of government spending (excluding and including military spending). ${ }^{12}$ The left panel of the table reports the size of the multipliers on output and consumption at different horizons (on impact, one-year, and two-year horizons, respectively). ${ }^{13}$ While the exact size of the estimated multipliers varies somewhat across specifications, the central finding of a positive response of consumption holds for the vast majority of cases. ${ }^{14}$

As mentioned above, some papers in the literature call into question (or at least qualify) the previous evidence. Perotti (2004) applies the methodology of Blanchard and Perotti (2002) to several OECD countries. He emphasizes the evidence of subsample instability in the effects of government spending shocks, with the responses in the $80 \mathrm{~s}$ and $90 \mathrm{~s}$ being more muted than in the earlier period. Nevertheless, the sign and magnitude of the response of private consumption in Perotti's estimates largely mimics that of GDP, both across countries and across sample periods. Hence,

\footnotetext{
${ }^{11}$ See Hemming, Kell and Mahfouz (2002) and the survey of the evidence provided in IMF (2004, chapter 2).

${ }^{12}$ See Table 1 for details.

${ }^{13}$ The right panel is used below for the purposes of model calibration.

${ }^{14}$ The only exception corresponds to the small VAR specification over the full sample period and excluding military spending. Yet, the underlying impulse responses (not shown) indicate that the slightly negative impact effect on consumption is quickly reversed in that case.
} 
his findings support a positive comovement between consumption and income, conditional on government spending shocks, in a way consistent with the model developed below (though at odds with the neoclassical model). ${ }^{15}$

Mountford and Uhlig (2004) apply the agnostic identification procedure originally proposed in Uhlig (1997) to identify and estimate the effects of a "balanced budget" and a "deficit spending" shock. ${ }^{16}$ They find that government spending shocks crowd out both residential and non-residential investment, but they hardly change consumption (the response of the latter is small and insignificant).

Ramey and Shapiro (1998) use a narrative approach to identify shocks that raise military spending, and which they codify by means of a dummy variable (widely known as the "Ramey-Shapiro dummy"). They find that nondurable consumption displays a slight, though hardly significant decline, while durables consumption falls persistently, but only after a brief but quantitatively large rise on impact. They also find that the product wage decreases, even though the real wage remains pretty much unchanged. ${ }^{17}$

Several other papers have used subsequently the identification scheme proposed by Ramey and Shapiro in order to study the effects of exogenous changes in government spending on different variables. Thus, Edelberg, Eichenbaum and Fisher (1999) show that a Ramey-Shapiro episode triggers a fall in real wages, an increase in nonresidential investment, and a mild and delayed fall in the consumption of nondurables and services, though durables consumption increases on impact. More recent work by Burnside, Eichenbaum and Fisher (2003) using a similar approach reports a flat response of aggregate consumption in the short run, followed by a small (and insignificant) rise in that variable several quarters after the Ramey-Shapiro episode is

\footnotetext{
${ }^{15}$ The response of private investment to the same shock tends to be negative, especially in the second sample period.

${ }^{16}$ This method is based on sign and near-zero restrictions on impulse responses.

${ }^{17}$ Ramey and Shapiro (1998) provide a potential explanation of the comovements of consumption and real wages in response to a change in military spending, based on a two-sector model with costly capital reallocation across sectors, and in which military expenditures are concentrated in one of the two sectors (manufacturing).
} 
triggered.

Another branch of the literature, exemplified by the work of Giavazzi and Pagano (1990), has uncovered the presence of "non-Keynesian effects" (i.e. negative spending multipliers) during large fiscal consolidations, with output rising significantly despite large cuts in government spending. In particular, Perotti (1999) finds evidence of a negative comovement of consumption and government spending during such episodes of fiscal consolidation (and hence large spending cuts), but only in circumstances of "fiscal stress" (defined by unusually high debt/GDP ratios). In "normal" times, however, the estimated effects have the opposite sign, i.e. they imply a positive response of consumption to a rise in government purchases. Nevertheless, as shown in Alesina and Ardagna (1998), the evidence of non-Keynesian effects during fiscal consolidations can hardly be interpreted as favorable to the neoclassical model since, on average, cuts in government spending raise both output and consumption during those episodes. ${ }^{18}$

Overall, we view the evidence discussed above as tending to favor the predictions of the traditional Keynesian model over those of the neoclassical model. In particular, none of the evidence appears to support the kind of strong negative comovement between output and consumption predicted by the neoclassical model in response to changes in government spending. Furthermore, in trying to understand some of the empirical discrepancies discussed above it is worth emphasizing that the bulk of the papers focusing on the response to changes in government spending in "ordinary" times tend to support the traditional Keynesian hypothesis, in contrast with those that focus on "extraordinary" fiscal episodes (associated with wars or with large fiscal consolidations triggered by explosive debt dynamics).

In light of those considerations, we view the model developed below as an attempt to account for the effects of government spending shocks in "normal" times, as opposed to extraordinary episodes. Accordingly, we explore the conditions under

\footnotetext{
${ }^{18}$ See Table 6 in Alesina and Ardagna (1998).
} 
which a dynamic general equilibrium model with nominal rigidities and rule-of-thumb consumers can account for the positive comovement of consumption and government purchases that arises in response to small exogenous variations in the latter variable.

\section{A New Keynesian Model with Rule-of-Thumb Consumers}

The economy consists of two types of households, a continuum of firms producing differentiated intermediate goods, a perfectly competitive firm producing a final good, a central bank in charge of monetary policy, and a fiscal authority. Next we describe the objectives and constraints of the different agents. Except for the presence of rule-of-thumb consumers, our framework consists of a standard dynamic stochastic general equilibrium model with staggered price setting à la Calvo. ${ }^{19}$

\subsection{Households}

We assume a continuum of infinitely-lived households, indexed by $i \in[0,1]$. A fraction $1-\lambda$ of households have access to capital markets where they can trade a full set of contingent securities, and buy and sell physical capital (which they accumulate and rent out to firms). We use the term optimizing or Ricardian to refer to that subset of households. The remaining fraction $\lambda$ of households do not own any assets nor have any liabilities, and just consume their current labor income. We refer to them as rule of thumb households. Different interpretations for that behavior include myopia, lack of access to capital markets, fear of saving, ignorance of intertemporal trading opportunities, etc. Our assumptions imply an admittedly extreme form of non-Ricardian behavior among rule of thumb households, but one that captures in a simple and parsimonious way some of the existing evidence, without invoking a

\footnotetext{
${ }^{19}$ Most of the recent monetary models with nominal rigidities abstract from capital accumulation. A list of exceptions includes King and Watson (1996), Yun (1996), Dotsey (1999), Kim (2000) and Dupor (2002). In our framework, the existence of a mechanism to smooth consumption over time is important in order for the distinction between Ricardian and non-Ricardian consumers to be meaningful, thus justifying the need for introducing capital accumulation explicitly.
} 
specific explanation. Campbell and Mankiw (1989) provide some aggregate evidence, based on estimates of a modified Euler equation, of the quantitative importance of such rule of thumb consumers in the U.S. and other industrialized economies. ${ }^{20}$

\subsubsection{Optimizing Households}

Let $C_{t}^{o}$, and $L_{t}^{o}$ represent consumption and leisure for optimizing households. Preferences are defined by the discount factor $\beta \in(0,1)$ and the period utility $U\left(C_{t}^{o}, L_{t}^{o}\right)$. A typical household of this type seeks to maximize

$$
E_{0} \sum_{t=0}^{\infty} \beta^{t} U\left(C_{t}^{o}, N_{t}^{o}\right)
$$

subject to the sequence of budget constraints

$$
P_{t}\left(C_{t}^{o}+I_{t}^{o}\right)+R_{t}^{-1} B_{t+1}^{o}=W_{t} P_{t} N_{t}^{o}+R_{t}^{k} P_{t} K_{t}^{o}+B_{t}^{o}+D_{t}^{o}-P_{t} T_{t}^{o}
$$

and the capital accumulation equation

$$
K_{t+1}^{o}=(1-\delta) K_{t}^{o}+\phi\left(\frac{I_{t}^{o}}{K_{t}^{o}}\right) K_{t}^{o}
$$

At the beginning of the period the consumer receives labor income $W_{t} P_{t} N_{t}^{o}$, where $W_{t}$ is the real wage, $P_{t}$ is the price level, and $N_{t}^{o}$ denotes hours of work. He also receives income from renting his capital holdings $K_{t}^{o}$ to firms at the (real) rental cost $R_{t}^{k}$. $B_{t}^{o}$ is the quantity of nominally riskless one-period bonds carried over from period $t-1$, and paying one unit of the numéraire in period $t$. $R_{t}$ denotes the gross nominal return on bonds purchased in period $t . D_{t}^{o}$ are dividends from ownership of firms, $T_{t}^{o}$ denote lump-sum taxes (or transfers, if negative) paid by these consumers. $C_{t}^{o}$ and $I_{t}^{o}$ denote, respectively, consumption and investment expenditures, in real terms. $P_{t}$ is the price of the final good. Capital adjustment costs are introduced through the term $\phi\left(\frac{I_{t}^{o}}{K_{t}^{o}}\right) K_{t}^{o}$, which determines the change in the capital stock induced by investment spending $I_{t}^{o}$. We assume $\phi^{\prime}>0$, and $\phi^{\prime \prime} \leq 0$, with $\phi^{\prime}(\delta)=1$, and $\phi(\delta)=\delta$.

\footnotetext{
${ }^{20}$ Mankiw (2000) reviews more recent microeconomic evidence consistent with that view.
} 
In what follows we specialize the period utility-common to all households- to take the form:

$$
U(C, L) \equiv \log C-\frac{N^{1+\varphi}}{1+\varphi}
$$

where $\varphi \geq 0$.

The first order conditions for the optimizing consumer's problem can be written as:

$$
\begin{gathered}
1=R_{t} E_{t}\left\{\Lambda_{t, t+1}\right\} \\
P_{t} Q_{t}=E_{t}\left\{\Lambda_{t, t+1}\left[R_{t+1}^{k}+Q_{t+1}\left((1-\delta)+\phi_{t+1}-\left(\frac{I_{t+1}^{o}}{K_{t+1}^{o}}\right) \phi_{t+1}^{\prime}\right)\right]\right\} \\
Q_{t}=\frac{1}{\phi^{\prime}\left(\frac{I_{t}^{o}}{K_{t}^{o}}\right)}
\end{gathered}
$$

where $\Lambda_{t, t+k}$ is the stochastic discount factor for real $k$-period ahead payoffs given by:

$$
\Lambda_{t, t+k} \equiv \beta^{k}\left(\frac{C_{t+k}^{o}}{C_{t}^{o}}\right)^{-1}
$$

and where $Q_{t}$ is the (real) shadow value of capital in place, i.e., Tobin's $Q$. Notice that, under our assumption on $\phi$, the elasticity of the investment-capital ratio with respect to $Q$ is given by $-\frac{1}{\phi^{\prime \prime}(\delta) \delta} \equiv \eta .^{21}$

We consider two alternative labor market structures. First we assume a competitive labor market, with each household choosing the quantity of hours supplied given the market wage. In that case the optimality conditions above must be supplemented with the first-order condition:

$$
W_{t}=C_{t}^{o}\left(N_{t}^{o}\right)^{\varphi}
$$

Under our second labor market structure wages are set in a centralized manner by an economy-wide union. In that case hours are assumed to be determined by firms (instead of being chosen optimally by households), given the wage set by the union. Households are willing to meet the demand from firms, under the assumption

\footnotetext{
${ }^{21}$ See Basu and Kimball (2003) for a critical assessment of the predictions of new Keynesian models with endogenous capital accumulation and a proposal for reconciling those predictions with some of the evidence, based on the notion of costly investment planning.
} 
that wages always remain above all households' marginal rate of substitution. In that case condition (8) no longer applies. We refer the reader to section 3.6 below and Appendix 1 for a detailed description of the labor market under this alternative assumption.

\subsubsection{Rule-of-Thumb Households}

Rule-of-thumb households are assumed to behave in a "hand-to-mouth" fashion, fully consuming their current labor income. They do not smooth their consumption path in the face of fluctuations in labor income, nor do they intertemporally substitute in response to changes in interest rates. As noted above we do not take a stand on the sources of that behavior, though one may possibly attribute it to a combination of myopia, lack of access to financial markets, or (continuously) binding borrowing constraints.

Their period utility is given by

$$
U\left(C_{t}^{r}, L_{t}^{r}\right)
$$

and they are subject to the budget constraint:

$$
P_{t} C_{t}^{r}=W_{t} P_{t} N_{t}^{r}-P_{t} T_{t}^{r}
$$

Accordingly, the level of consumption will equate labor income net of taxes:

$$
C_{t}^{r}=W_{t} N_{t}^{r}-T_{t}^{r}
$$

Notice that we allow taxes paid by rule-of-thumb households $\left(T_{t}^{r}\right)$ to differ from those of the optimizing households $\left(T_{t}^{o}\right)$. Under the assumption of a competitive labor market, the labor supply of rule-of-thumb households must satisfy:

$$
W_{t}=C_{t}^{r}\left(N_{t}^{r}\right)^{\varphi}
$$

Alternatively, when the wage is set by a union, hours are determined by firms' labor demand, and (8) does not apply. Again we refer the reader to the discussion below. 


\subsubsection{Aggregation}

Aggregate consumption and hours are given by a weighted average of the corresponding variables for each consumer type. Formally:

$$
C_{t} \equiv \lambda C_{t}^{r}+(1-\lambda) C_{t}^{o}
$$

and

$$
N_{t}=\lambda N_{t}^{r}+(1-\lambda) N_{t}^{o}
$$

Similarly, aggregate investment and the capital stock are given by

$$
I_{t} \equiv(1-\lambda) I_{t}^{o}
$$

and

$$
K_{t} \equiv(1-\lambda) K_{t}^{o}
$$

\subsection{Firms}

We assume a continuum of monopolistically competitive firms producing differentiated intermediate goods. The latter are used as inputs by a (perfectly competitive) firm producing a single final good.

\subsubsection{Final Goods Firm}

The final good is produced by a representative, perfectly competitive firm with a constant returns technology:

$$
Y_{t}=\left(\int_{0}^{1} X_{t}(j)^{\frac{\epsilon_{p}-1}{\epsilon_{p}}} d j\right)^{\frac{\epsilon_{p}}{\epsilon_{p}-1}}
$$

where $X_{t}(j)$ is the quantity of intermediate good $j$ used as an input and $\epsilon_{p}>1$. Profit maximization, taking as given the final goods price $P_{t}$ and the prices for the intermediate goods $P_{t}(j)$, all $j \in[0,1]$, yields the set of demand schedules

$$
X_{t}(j)=\left(\frac{P_{t}(j)}{P_{t}}\right)^{-\epsilon_{p}} Y_{t}
$$

as well as the zero profit condition $P_{t}=\left(\int_{0}^{1} P_{t}(j)^{1-\epsilon_{p}} d j\right)^{\frac{1}{1-\epsilon_{p}}}$. 


\subsubsection{Intermediate Goods Firm}

The production function for a typical intermediate goods firm (say, the one producing good $j$ ) is given by:

$$
Y_{t}(j)=K_{t}(j)^{\alpha} N_{t}(j)^{1-\alpha}
$$

where $K_{t}(j)$ and $N_{t}(j)$ represent the capital and labor services hired by firm $j \cdot{ }^{22}$ Cost minimization, taking the wage and the rental cost of capital as given, implies:

$$
\frac{K_{t}(j)}{N_{t}(j)}=\left(\frac{\alpha}{1-\alpha}\right)\left(\frac{W_{t}}{R_{t}^{k}}\right)
$$

Real marginal cost is common to all firms and given by:

$$
M C_{t}=\Psi\left(R_{t}^{k}\right)^{\alpha}\left(W_{t}\right)^{1-\alpha}
$$

where $\Psi \equiv \alpha^{-\alpha}(1-\alpha)^{-(1-\alpha)}$.

Price Setting Intermediate firms are assumed to set nominal prices in a staggered fashion, according to the stochastic time dependent rule proposed by Calvo (1983). Each firm resets its price with probability $1-\theta$ each period, independently of the time elapsed since the last adjustment. Thus, each period a measure $1-\theta$ of producers reset their prices, while a fraction $\theta$ keep their prices unchanged.

A firm resetting its price in period $t$ will seek to maximize

$$
\max _{P_{t}^{*}} E_{t} \sum_{k=0}^{\infty} \theta^{k} E_{t}\left\{\Lambda_{t, t+k} Y_{t+k}(j)\left(\left(P_{t}^{*} / P_{t+k}\right)-M C_{t+k}\right)\right\}
$$

subject to the sequence of demand constraints $Y_{t+k}(j)=X_{t+k}(j)=\left(\frac{P_{t}^{*}}{P_{t+k}}\right)^{-\epsilon_{p}} Y_{t+k}$ and where $P_{t}^{*}$ represents the price chosen by firms resetting prices at time $t$.

The first order condition for the above problem is:

$$
\sum_{k=0}^{\infty} \theta^{k} E_{t}\left\{\Lambda_{t, t+k} Y_{t+k}(j)\left(\left(P_{t}^{*} / P_{t+k}\right)-\mu^{p} M C_{t+k}\right)\right\}=0
$$

\footnotetext{
${ }^{22}$ Without loss of generality we normalize total factor productivity to unity.
} 
where $\mu^{p} \equiv \frac{\epsilon_{p}}{\epsilon_{p}-1}$ is the gross "frictionless" price markup, and the one prevailing in a zero inflation steady state. Finally, the equation describing the dynamics for the aggregate price level is given by:

$$
P_{t}=\left[\theta P_{t-1}^{1-\epsilon_{p}}+(1-\theta)\left(P_{t}^{*}\right)^{1-\epsilon_{p}}\right]^{\frac{1}{1-\epsilon_{p}}}
$$

\subsection{Monetary Policy}

In our baseline model the central bank is assumed to set the nominal interest rate $r_{t} \equiv R_{t}-1$ every period according to a simple linear interest rate rule:

$$
r_{t}=r+\phi_{\pi} \pi_{t}
$$

where $\phi_{\pi} \geq 0$ and $r$ is the steady state nominal interest rate. An interest rate rule of the form (18) is the simplest specification in which the conditions for indeterminacy and their connection to the Taylor principle can be analyzed. Notice that it is a particular case of the celebrated Taylor rule (Taylor (1993)), corresponding to a zero coefficient on the output gap, and a zero inflation target. Rule (18) is said to satisfy the Taylor principle if and only if $\phi_{\pi}>1$. As is well known, in the absence of rule-of-thumb consumers, that condition is necessary and sufficient to guarantee the uniqueness of equilibrium. ${ }^{23}$

\subsection{Fiscal Policy}

The government budget constraint is

$$
P_{t} T_{t}+R_{t}^{-1} B_{t+1}=B_{t}+P_{t} G_{t}
$$

where $T_{t} \equiv \lambda T_{t}^{r}+(1-\lambda) T_{t}^{o}$. Letting $g_{t} \equiv \frac{G_{t}-G}{Y}, t_{t} \equiv \frac{T_{t}-T}{Y}$, and $b_{t} \equiv \frac{\left(B_{t} / P_{t-1}\right)-(B / P)}{Y}$, we henceforth assume a fiscal policy rule of the form

$$
t_{t}=\phi_{b} b_{t}+\phi_{g} g_{t}
$$

\footnotetext{
${ }^{23}$ The "Taylor principle" refers to a property of interest rate rules for which an increase in inflation eventually leads to a more than one-for-one rise in the nominal interest rate (see Woodford (2001)).
} 
where $\phi_{b}$ and $\phi_{g}$ are positive constants.

Finally, government purchases (in deviations from steady state, and normalized by steady state output) are assumed to evolve exogenously according to a first order autoregressive process:

$$
g_{t}=\rho_{g} g_{t-1}+\varepsilon_{t}
$$

where $0<\rho_{g}<1$, and $\varepsilon_{t}$ represents an i.i.d. government spending shock with constant variance $\sigma_{\varepsilon}^{2}$.

\subsection{Market Clearing}

The clearing of factor and good markets requires that the following conditions are satisfied for all $t$ :

$$
\begin{gathered}
N_{t}=\int_{0}^{1} N_{t}(j) d j \\
K_{t}=\int_{0}^{1} K_{t}(j) d j \\
Y_{t}(j)=X_{t}(j) \quad \text { for all } j
\end{gathered}
$$

and

$$
Y_{t}=C_{t}+I_{t}+G_{t}
$$

\subsection{Linearized Equilibrium Conditions}

In the present section we derive the log-linear versions of the key optimality and market clearing conditions that will be used in our analysis of the model's equilibrium dynamics. Some of these conditions hold exactly, while others represent first-order approximations around a zero-inflation steady state. Henceforth, and unless otherwise noted, lower case letters denote log-deviations with respect to the corresponding steady state values (i.e., $x_{t} \equiv \log \frac{X_{t}}{X}$ ). 


\subsubsection{Households}

Next we list the log-linearized versions of the above households' optimality conditions, expressed in terms of the aggregate variables. The log-linear equations describing the dynamics of Tobin's $Q$ and its relationship with investment are given respectively by

$$
q_{t}=\beta E_{t}\left\{q_{t+1}\right\}+[1-\beta(1-\delta)] E_{t}\left\{r_{t+1}^{k}\right\}-\left(r_{t}-E_{t}\left\{\pi_{t+1}\right\}\right)
$$

and

$$
i_{t}-k_{t}=\eta q_{t}
$$

The log-linearized capital accumulation equation is:

$$
k_{t+1}=\delta i_{t}+(1-\delta) k_{t}
$$

The log-linearized Euler equation for optimizing households is given by

$$
c_{t}^{o}=E_{t}\left\{c_{t+1}^{o}\right\}-\left(r_{t}-E_{t}\left\{\pi_{t+1}\right\}\right)
$$

Consumption for rule-of-thumb households is given, to a first order approximation by

$$
c_{t}^{r}=\left(\frac{W N^{r}}{C^{r}}\right)\left(w_{t}+n_{t}^{r}\right)-\left(\frac{Y}{C^{r}}\right) t_{t}^{r}
$$

where $t_{t}^{r} \equiv \frac{T_{t}^{r}-T^{r}}{Y}$.

As shown in the Appendix, the analysis is simplified by assuming that steady state consumption is the same across household types, i.e. $C^{r}=C^{o}=C$, an outcome that can always be guaranteed by an appropriate choice of $T^{r}$ and $T^{o}$. Since the focus of our paper is on the differential responses to shocks, as opposed to steady state differences across households, we view that assumption as being largely innocuous, while simplifying the algebra considerably. ${ }^{24}$ In particular, under the above assumption,

\footnotetext{
${ }^{24}$ Notice that under perfectly competitive labor markets marginal rates of substitution are equalized across households. The assumption of equal consumption levels in the steady state thus implies that $\mathbf{N}^{r}=\mathrm{N}^{o}=\mathrm{N}$ as well. As discussed below, under our alternative labor market structure equality of hours across household types holds independently of their relative level of consumption. See Appendix 1 for details.
} 
the log-linearized expressions for aggregate consumption and hours take the following simple form:

$$
c_{t}=\lambda c_{t}^{r}+(1-\lambda) c_{t}^{o}
$$

and

$$
n_{t}=\lambda n_{t}^{r}+(1-\lambda) n_{t}^{o}
$$

Under perfectly competitive labor markets, we can log-linearize expressions (8), (12), and combine them with (28) and (29) to obtain:

$$
w_{t}=c_{t}+\varphi n_{t}
$$

Under the assumption of imperfectly competitive labor markets, one can also interpret equation (30) as a log-linear approximation to a generalized wage schedule of the form $W_{t}=H\left(C_{t}, N_{t}\right)$. In that case, and under the assumption that each firm decides how much labor to hire (given the wage), firms will allocate labor demand uniformly across households, independently of their type. Accordingly, we will have $N_{t}^{r}=N_{t}^{o}$ for all $t .{ }^{25}$ In Appendix 1 we show how a wage schedule of that form arises in an economy in which wages are set by unions in order to maximize a weighted average of the utility of both types of households.

Independently of the assumed labor market structure we can derive an intertemporal equilibrium condition for aggregate consumption of the form:

$$
c_{t}=E_{t}\left\{c_{t+1}\right\}-\sigma\left(r_{t}-E_{t}\left\{\pi_{t+1}\right\}\right)-\Theta_{n} E_{t}\left\{\Delta n_{t+1}\right\}+\Theta_{\tau} E_{t}\left\{\Delta t_{t+1}^{r}\right\}
$$

In the case of perfectly competitive labor markets, the previous equation results from combining (8), (12), (26), (27), (28) and (29), and the associated coefficients are

\footnotetext{
${ }^{25}$ We implicitly assume that the resulting wage markup is sufficiently high (and fluctuations sufficiently small) that the inequalities $\mathbf{H}\left(\mathrm{C}_{t}, \mathrm{~N}_{t}\right)>\mathrm{C}_{t}^{j} \mathrm{~N}_{t}^{\varphi}$ for $\mathrm{j}=\mathrm{r}, \mathrm{o}$ are satisfied at all times. Both conditions guarantee that both type of households will be willing to meet firms' labor demand at the prevaling wage. Notice also that consistency with balanced-growth requires that $\mathrm{H}$ can be written as $\mathrm{C}_{t} \mathrm{~h}\left(\mathrm{~N}_{t}\right)$ (which happens to be consistent with (30)).
} 
given by:

$$
\begin{aligned}
\sigma & \equiv(1-\lambda) \Gamma\left[\mu^{p} \varphi \gamma_{c}+(1-\alpha)\right] \\
\Theta_{n} & \equiv \lambda \Gamma(1-\alpha)(1+\varphi) \varphi \\
\Theta_{t} & \equiv \lambda \Gamma \mu^{p} \varphi
\end{aligned}
$$

where $\Gamma \equiv \frac{1}{\mu^{p} \varphi \gamma_{c}+(1-\alpha)(1-\lambda(1+\varphi))}$, and $\gamma_{c} \equiv \frac{C}{Y}$ is the steady state consumption-output ratio (which, does not depend on $\lambda$, as shown in Appendix 2 ). See Appendix 3 for details of the derivation.

By contrast, under the assumption of an imperfectly competitive labor market, (31) can be derived from combining (30), (26), (27), (28), (29), as well as the assumption $n_{t}^{r}=n_{t}^{o}=n_{t}$. In that case the expressions for the coefficients in (31) are given by:

$$
\begin{aligned}
\sigma & \equiv(1-\lambda) \Phi \gamma_{c} \mu^{p} \\
\Theta_{n} & \equiv \lambda \Phi(1-\alpha)(1+\varphi) \\
\Theta_{t} & \equiv \lambda \Phi \mu^{p}
\end{aligned}
$$

where $\Phi \equiv \frac{1}{\gamma_{c} \mu^{p}-\lambda(1-\alpha)}$.

Notice that independently of the labor market structure assumed we have $\lim _{\lambda \rightarrow 0}$ $\sigma=1, \lim _{\lambda \rightarrow 0} \Theta_{n}=0$, and $\lim _{\lambda \rightarrow 0} \Theta_{\tau}=0$, i.e., as the fraction of rule-of-thumb consumers becomes negligible, the aggregate Euler equation approaches its standard form given our utility specification.

Discussion A number of features of the above equilibrium conditions are worth stressing. First, notice that the Euler equation (31) is the only log-linear equilibrium condition involving aggregate variables which displays a dependence on $\lambda$, the fraction of rule of thumb households..

Second, the presence of rule-of-thumb households generates a direct effect of employment on the level of consumption (and, thus, on aggregate demand), beyond the 
effect of the long-term interest rate. This can be seen by "integrating" (31) to obtain the following expression in levels:

$$
c_{t}=\Theta_{n} n_{t}-\Theta_{\tau} t_{t}^{r}-\sigma \sum_{k=0}^{\infty} E_{t}\left\{r_{t+k}-\pi_{t+k+1}\right\}
$$

Thus, for any given path of real interest rates and taxes, an expansion in government purchases has the potential to raise aggregate consumption through its induced expansion in employment and the consequent rise in the real wage, labor income and, as a result, consumption of rule-of-thumb households. In turn, the resulting increase in consumption would raise aggregate demand, output and employment even further, thus triggering a multiplier effect analogous to the one found in traditional Keynesian models.

Third, the ultimate effect of government purchases on aggregate consumption depends on the response of taxes (accruing to rule-of-thumb households) and the expected long term real rate. Those responses will, in turn, be determined by the fiscal and monetary policy rules in place. Nevertheless, it is clear from the previous equation that in order for aggregate consumption to increase in response to a rise in government spending, the response of taxes and interest rates should be sufficiently muted. We return to this point below, when analyzing the sensitivity of our results to alternative calibrations of those policies.

\subsubsection{Firms}

Log-linearization of (16) and (17) around the zero inflation steady state yields the familiar equation describing the dynamics of inflation as a function of the log deviations of the average markup from its steady state level

$$
\pi_{t}=\beta E_{t}\left\{\pi_{t+1}\right\}-\lambda_{p} \widehat{\mu}_{t}^{p}
$$

where $\lambda_{p}=\frac{(1-\beta \theta)(1-\theta)}{\theta}$ and, ignoring constant terms,

$$
\widehat{\mu}_{t}^{p}=\left(y_{t}-n_{t}\right)-w_{t}
$$


or, equivalently,

$$
\widehat{\mu}_{t}^{p}=\left(y_{t}-k_{t}\right)-r_{t}^{k}
$$

Furthermore, as shown in Woodford (2003), the following "aggregate production function" holds, up to a first order approximation:

$$
y_{t}=(1-\alpha) n_{t}+\alpha k_{t}
$$

\subsubsection{Market clearing}

Log-linearization of the market clearing condition of the final good around the steady state yields:

$$
y_{t}=\gamma_{c} c_{t}+\gamma_{i} i_{t}+g_{t}
$$

where $\gamma_{i} \equiv \frac{I}{Y}$ represents the share of investment on output in the steady state.

\subsubsection{Fiscal Policy}

Linearization of the government budget constraint (19) around a steady state with zero debt and a balanced primary budget yields

$$
b_{t+1}=(1+\rho)\left(b_{t}+g_{t}-t_{t}\right)
$$

where $\rho \equiv \beta^{-1}-1$ pins down the steady state interest rate. Plugging in the fiscal policy rule assumed above we obtain:

$$
b_{t+1}=(1+\rho)\left(1-\phi_{b}\right) b_{t}+(1+\rho)\left(1-\phi_{g}\right) g_{t}
$$

Hence, under our assumptions, a necessary and sufficient condition for non-explosive debt dynamics is given by $(1+\rho)\left(1-\phi_{b}\right)<1$, or equivalently

$$
\phi_{b}>\frac{\rho}{1+\rho}
$$




\section{Analysis of Equilibrium Dynamics}

Combining all the equilibrium conditions and doing some straightforward, though tedious, substitutions we can obtain a system of stochastic difference equations describing the log-linearized equilibrium dynamics of the form

$$
\text { A } E_{t}\left\{\mathbf{x}_{t+1}\right\}=\mathrm{B} \mathbf{x}_{t}+\varepsilon_{t}
$$

where $\mathbf{x}_{t} \equiv\left(n_{t}, c_{t}, \pi_{t}, k_{t}, b_{t}, g_{t-1}\right)^{\prime}$. The elements of matrices $\mathrm{A}$ and $\mathrm{B}$ are all functions of the underlying structural parameters, as shown in Appendix 3. We start by describing the calibration that we use as a benchmark.

Each period is assumed to correspond to a quarter. We set the discount factor $\beta$ equal to 0.99 . We assume a steady state price markup $\mu^{p}$ equal to 0.2 . The rate of depreciation $\delta$ is set to 0.025 . The elasticity of output with respect to capital, $\alpha$, is assumed to be $\frac{1}{3}$, a value roughly consistent with observed income shares, given the assumed steady state price markup. All the previous parameter values remain unchanged in the analysis below. Next we turn to the parameters for which we conduct some sensitivity analysis, distinguishing between the non-policy and the policy parameters.

Our baseline setting for the weight of rule-of-thumb households $\lambda$ is $\frac{1}{2}$. This is within the range of estimated values in the literature of the weight of the rule-ofthumb behavior (see Mankiw (2000)). The fraction of firms that keep their prices unchanged, $\theta$, is given a baseline value of 0.75 , which corresponds to an average price duration of one year. We set the baseline value for the elasticity of wages with respect to hours $(\varphi)$ equal to 0.2. This is consistent with Rotemberg and Woodford's (1997, 1999) calibration of the elasticity of wages with respect to output of 0.3 combined with an elasticity of output with respect to hours of $\frac{2}{3}$. Finally, we follow King and Watson (1996), and set $\eta$ (the elasticity of investment with respect to $q$ ) equal to 1.0 in our baseline calibration.

The baseline policy parameters are chosen as follows. We set the size of the 
response of the monetary authority to inflation, $\phi_{\pi}$, to 1.5 , a value commonly used in empirical Taylor rules (and one that satisfies the so-called Taylor principle). In order to calibrate the parameters describing the fiscal policy rule (20) and the government spending shock $(21)$ (i.e. $\phi_{g}, \phi_{b}$, and $\rho_{g}$ ) we use the VAR-based estimates of the dynamic responses of government spending and deficit (see Table 1 for details). In particular, we set the baseline value of the parameter $\rho_{g}=0.9$ that matches the half-life of the responses of government spending. The latter value reflects the highly persistent response of government spending to its own shock. We obtain the values of the parameter $\phi_{g}$ from the difference between the estimated impact responses of government spending and deficit, respectively. As can be seen from Table 1, our (average) estimates suggest a value for that parameter equal to 0.10. Interestingly, the estimates in Table IV of Blanchard and Perotti (2002) imply a corresponding estimate of 0.13 , very much in line with our estimates and baseline calibration. Finally, and given $\rho_{g}$ and $\phi_{g}$, we calibrate parameter $\phi_{b}$ such that the dynamics of government spending (21) and debt (37) are consistent with the horizon at which the deficit is back to zero in our estimates. Hence, in our baseline calibration we set $\phi_{b}=0.33$, in line with the estimated averages for different subsamples, as described in Table 1. Finally, we set $\gamma_{g}=0.2$, which roughly corresponds to the average share of government purchases in GDP in postwar U.S. data.

Much of the sensitivity analysis below focuses on the share of rule-of-thumb households $(\lambda)$ and its interaction with parameters $\rho_{g}, \theta, \eta, \varphi$ and $\phi_{\pi}$. Given the importance of the fiscal rule parameters in the determination of aggregate consumption (and, indirectly, of other variables) we will also analyze the effect of alternative values for the policy parameters $\phi_{b}$ and $\phi_{g}$. 


\subsection{Rule-of-Thumb Consumers, Indeterminacy, and the Tay- lor Principle}

Next we provide a brief analysis of the conditions that guarantee the uniqueness of equilibrium. A more detailed analysis of those conditions for an economy similar to the one considered here (albeit without a fiscal block) can be found in Galí, LópezSalido and Vallés (2004). In that paper we show how the presence of rule-of-thumb consumers can alter dramatically the equilibrium properties of an otherwise standard dynamic sticky price model. In particular, under certain parameter configurations the economy's equilibrium may be indeterminate (and thus may display stationary sunspot fluctuations) even when the interest rate rule is one that satisfies the Taylor principle (which corresponds to $\phi_{\pi}>1$ in our model).

Figure 2 illustrates that phenomenon for the model developed in the previous section. In particular the figure displays the regions in $(\lambda, \theta)$ space associated with either a unique equilibrium or indeterminacy, when the remaining parameters are kept at their baseline values. We see that indeterminacy arises whenever a high degree of price stickiness coexists with a sufficiently large weight of rule-of-thumb households. Both frictions are thus seen to be necessary in order for indeterminacy to emerge as a property of the equilibrium dynamics. The figure also makes clear that the equilibrium is unique under our baseline calibration $\left(\lambda=\frac{1}{2}, \theta=0.75\right)$. We refer the reader to Galí, López-Salido and Vallés (2004) for a discussion of the intuition underlying that violation of the Taylor principle. ${ }^{26}$

\section{The Effects of Government Spending Shocks}

In the present section we analyze the effects of shocks to government spending in the model economy described above. In particular, we focus on the conditions under which an exogenous increase in government spending has a positive effect on

\footnotetext{
${ }^{26}$ See also Bilbiie (2005) for a subsequent analysis in a model without capital accumulation, and for a re-assessment of the evolution of Fed policies over the postwar period, in light of that analysis.
} 
consumption, as found in much of the existing evidence. Throughout we restrict ourselves to configurations of parameter values for which the equilibrium is unique.

Figure 3 shows the contemporaneous response of output, consumption and investment (all normalized by steady state output) to a positive government spending shock, as a function of $\lambda$, the fraction of rule-of-thumb consumers. The size of the shock is normalized to a one percent of steady state output. Given the above normalizations, the plotted values can be interpreted as impact multipliers. We restrict the range of $\lambda$ values considered to those consistent with a unique equilibrium. The remaining parameters are kept at their baseline values. Figure 3.A corresponds to the economy with competitive labor markets, Figure 3.B to its imperfectly competitive counterpart. In the former case, consumption declines for most values of $\lambda$ considered, except for implausible large ones. The (absolute) size of the decline is, however, decreasing in $\lambda$, reflecting the offsetting role of rule-of-thumb behavior on the conventional negative wealth and intertemporal substitution effects triggered by the fiscal expansion. When imperfect labor markets are assumed, the possibility of crowding-in of consumption emerges for values of $\lambda$ above a threshold value of roughly $\frac{1}{4}$, a more plausible value. Notice also that the government spending multiplier on inflation and output rises rapidly when $\lambda$ increases, attaining values roughly in line with the empirical evidence reviewed in section 2.

Figure 4 displays the dynamic responses of some key variables in our model to a positive government spending shock under the baseline calibration, and compares them to those generated by a neoclassical economy. The latter corresponds to a particular calibration of our model, with no price rigidities and no rule-of-thumb consumers $(\theta=\lambda=0)$. Again we consider two alternative labor market structures, competitive and non-competitive. In each case the top-left graph displays the pattern of the three fiscal variables (spending, taxes and the deficit) in response to the shock considered. Notice that the pattern of both variables is close to the one estimated in the data (see Figure 1), consistently with our calibration of the fiscal policy rule. The figures 
illustrates the amplifying effects of the introduction of rule-of-thumb consumers and sticky prices: the response of output and consumption is systematically above that generated by the neoclassical model. ${ }^{27}$ Furthermore, in the baseline model, and in contrast with the neoclassical model, the increase in aggregate hours coexists with an increase in real wages. Overall we view the model's predictions under the assumption of imperfectly competitive labor markets as matching the empirical responses, at least qualitatively.

Figure 5 shows the government spending (impact) multipliers on output, consumption, and investment, as a function of $\rho_{g}$, the parameter measuring the persistence of the spending process. In order to avoid excessive dispersion, we henceforth report findings only for the non-competitive labor market specification, which the analysis above pointed to as the most promising one given our objectives. Each of the four graphs in the Figure corresponds to a different parameter configuration. The top-left graph is associated with our baseline calibration. Notice that that in that case the crowding-in effect on consumption (and the consequent enhancement of the output multiplier) is decreasing in $\rho_{g}$. The intuition for that result is straightforward: higher values of that parameter are associated with stronger (negative) wealth effects lowering the consumption of Ricardian households. Yet, we see that even for values of $\rho_{g}$ as high as 0.9 a positive (though relatively small) effect on aggregate consumption emerges. Notice also that the response of investment to the same shock is negative over the admissible range of $\rho_{g}$. Yet, for values of the latter parameter close to unity (i.e., near-random walk processes for government spending) that response becomes negligible. ${ }^{28}$

The other graphs in Figure 5 report analogous information for three alternative

\footnotetext{
${ }^{27}$ That monotonicity contrasts with some of the patterns observed in the data; we conjecture this is unrelated to the issue at hand and could be fixed by the introduction of habit formation and other mechanisms that generate inertia in aggregate demand.

${ }^{28}$ As shown below the response of investment depend crucially upon the specification of capital adjustment costs. Lower capital adjustment costs tend to increase the (negative) response of investment (see middle panel of Figure 6).
} 
"extreme" calibrations. Each calibration assumes a limiting value for one (or two) parameters, while keeping the rest at their baseline values. Thus, the flexible price scenario assumes $\theta=0$, the no rule-of-thumb economy assumes $\lambda=0$, whereas the neoclassical calibration combines both flexible prices and lack of rule-of-thumb consumers $(\theta=\lambda=0)$. Notice that when prices are fully flexible, or when all consumers are Ricardian (or when both features coexist, as under the neoclassical calibration) consumption is always crowded-out in response to a rise in government spending, independently of the degree of persistence of the latter. This illustrates the difficulty of reconciling the evidence with standard dynamic general equilibrium models, as well as the role played by both sticky prices and rule-of-thumb consumers to match that evidence.

The graphs in Figure 6 summarize the sensitivity of the impact multipliers to variations in three non-policy parameters to the government spending shock. The first graph explores the sensitivity of the impact multipliers to the degree of price stickiness, as indexed by parameter $\theta$. Notice that the size of the response of output is increasing in the degree of price rigidities, largely as a result of a stronger multiplier effect on consumption. Given baseline values for the remaining parameters, we see that values of $\theta$ slightly higher than 0.5 are consistent with a positive response of aggregate consumption. That range for $\theta$ includes the values generally viewed as consistent with the micro evidence and, hence, used in most calibrations. The two middle and bottom graphs show the impact multipliers when the degree of capital adjustment costs, $\eta$, and the wage elasticity parameter, $\varphi$ change. High capital adjustment costs (i.e., low $\eta$ ) tend to dampen the fall in investment, but enhance the positive response of consumption and output. Finally, we notice that the impact multipliers are relatively insensitive to changes in $\varphi$.

Figure 7 illustrates the sensitivity of the model's predictions to the three policy parameters $\left(\phi_{\pi}, \phi_{g}, \phi_{b}\right)$, each considered in turn. The top graph shows an inverse relationship between the size of the impact multipliers and the strength of the central 
bank's response to inflation $\left(\phi_{\pi}\right)$. Intuitively, a large $\phi_{\pi}$ leads to a larger increase in the real rate in response to the higher inflation induced by the fiscal expansion; as a result consumption of Ricardian households declines further, dampening the total effect on aggregate consumption. That finding should not be surprising once we realize that in staggered price setting models like ours the central bank can approximate arbitrarily well the flexible price equilibrium allocation by following an interest rate rule that responds with sufficient strength to changes in inflation. Hence, an increase in $\phi_{\pi}$ affects the output and consumption multipliers in a way qualitatively similar to an increase in price flexibility (i.e. a decline in $\theta$ ), as described above.

Finally, the second and third graphs show the sensitivity of the multiplier to variations in the two parameters of the fiscal rule. In particular, and of most interest given our objectives, we see how a positive comovement of consumption and output in response to government spending shocks requires a sufficiently high response of taxes to debt (a high $\phi_{b}$ ), and a sufficiently low response of taxes to current government spending (i.e. a low $\phi_{g}$ ). Such a configuration of fiscal parameters will tend to imply a large but not-too-persistent deficit in response to an increase in government spending, a pattern largely consistent with the empirical evidence described in Section 2.

\section{Summary and Assessment of the Model}

The analysis above has shown how the interaction between rule-of-thumb behavior by some households (for which consumption equals labor income) and sticky prices (modeled as in the recent new Keynesian literature), make it possible to generate an increase in consumption in response to a persistent expansion in government spending, in a way consistent with much of the recent evidence. Rule-of-thumb consumers partly insulate aggregate demand from the negative wealth effects generated by the higher levels of (current and future) taxes needed to finance the fiscal expansion, while making it more sensitive to current disposable income. Sticky prices make it possible for real wages to increase (or, at least, to decline by a smaller amount) even in the face 
of a drop in the marginal product of labor, as the price markup may adjust sufficiently downward to absorb the resulting gap. The combined effect of a higher real wage and higher employment raises current labor income and hence stimulates the consumption of rule-of-thumb households. The possible presence of countercyclical wage markups (as in the version of the model with non-competitive labor markets developed above) provides additional room for a simultaneous increase in consumption and hours and, hence, in the marginal rate of substitution, without requiring a proportional increase in the real wage.

Most importantly, our framework generates a positive comovement of consumption and government spending under configurations of parameter values that are empirically plausible, and those conventionally assumed in the business cycle literature. Thus, we view our results as providing a potential solution to the seeming conflict between empirical evidence and the predictions of existing DSGE models regarding the effects of government spending shocks.

In the present paper we kept both the model and its analysis as simple as possible, and focused on a single issue. As a result, we left out many possible extensions and avenues for further exploration. Thus, for instance, our theoretical analysis assumes that government spending is financed by means of lump-sum taxes (current or future). If only distortionary income taxes were available to the government, the response of the different macroeconomic variables to a government spending shock will generally differ from the one obtained in the economy with lump-sum taxes analyzed above, and will depend on the composition and timing of the taxation. ${ }^{29}$

Allowing for staggered nominal wage setting or some form of real wage rigidity constitutes another potentially useful extension of our framework, one that is likely to have a significant effect on the response of real wages and, hence, of labor income and consumption to any fiscal shock.

\footnotetext{
${ }^{29}$ An example of work in that direction is given by Bilbiie and Straub (2004), who study the interaction of distortionary taxes and rule of thumb households, albeit in a model without capital accumulation.
} 
Another avenue worth pursuing is the introduction of rule-of-thumb consumers in medium-scale DSGE models of the sort developed by Smets and Wouters (2003) and Christiano, Eichenbaum and Evans (2005). Those models incorporate many of the features that have been shown to be useful in accounting for different aspects of economic fluctuations, and which have been assumed away in the model developed above. Such a richer version of our model could be taken to the data, and generate estimates of the quantitative importance of rule of thumb consumers and their role in shaping historical economic fluctuations. ${ }^{30}$

A number of papers have documented a stronger interest rate response to changes in inflation during the past two decades, relative to the pre-Volcker era. ${ }^{31}$ There is also substantial evidence pointing to a rise in asset market participation over the postwar period, which in the context of our model could be interpreted as a decline in the fraction of rule of thumb consumers. The model developed above predicts a reduction in the government spending multiplier on consumption and output, in response to both developments. In that spirit, Bilbiie, Meier and Muller (2005) explore the implications of those changes in the context of a model similar to ours, and suggest those developments may explain part of the observed decline in fiscal multipliers uncovered by Perotti (2004) and others.

Finally, one would want to consider some of the normative implications of our framework: in a model with the two types of consumers considered above, the monetary and fiscal policy responses to shocks of different nature can be expected to have distributional effects, which should be taken into account in the design of those policies. Exploring the implications of the present model for optimal monetary policy design constitutes an additional interesting avenue for future research. ${ }^{32}$

\footnotetext{
${ }^{30}$ See Coenen and Straub (2004) and Erceg, Guerrieri and Gust (2005) for promising early efforts in that direction.

${ }^{31}$ See, e.g. Clarida, Galí and Gertler (2000).

${ }^{32}$ This is the road taken by Amato and Laubach (2003), albeit in the context of an alternative model of rule-of-thumb behavior.
} 


\section{Appendix 1: Alternative Labor Market Structures}

In the present Appendix we describe two alternative models of wage determination that generate a log-linear aggregate equilibrium condition corresponding to (30) in the text.

\section{Perfectly Competitive Labor Markets}

When households choose optimally their labor supply taking wages as given the intratemporal optimality condition takes the form,

$$
W_{t}=C_{t}^{j}\left(N_{t}^{j}\right)^{\varphi}
$$

or, in $\operatorname{logs}$

$$
w_{t} \equiv c_{t}^{j}+\varphi n_{t}^{j}
$$

for $j=r, o$.

Notice that under our assumption of equality of steady state consumption across household types, steady state hours will also be equated. Hence we can write

$$
n_{t}=\lambda n_{t}^{r}+(1-\lambda) n_{t}^{o}
$$

which together with (28) and (39) allows us to obtain the aggregate equilibrium condition

$$
w_{t} \equiv c_{t}+\varphi n_{t}
$$

\section{Wage-setting by Unions}

Consider a model with a continuum of unions, each of which represents workers of a certain type. Effective labor input hired by firm $j$ is a CES function of the quantities of the different labor types employed,

$$
N_{t}(j)=\left(\int_{0}^{1} N_{t}(j, i)^{\frac{\epsilon_{w}-1}{\epsilon_{w}}} d i\right)^{\frac{\epsilon_{w}}{\epsilon_{w}-1}}
$$


where $\epsilon_{w}$ is the elasticity of substitution across different types of households. The fraction of rule-of-thumb and Ricardian consumers is uniformly distributed across worker types (and hence across unions). Each period, a typical union (say, representing worker of type $z$ ) sets the wage for its workers in order to maximize the objective function

$$
\max \lambda\left[\frac{1}{C_{t}^{r}(z)} W_{t}(z) N_{t}(z)-\frac{N_{t}^{1+\varphi}(z)}{1+\varphi}\right]+(1-\lambda)\left[\frac{1}{C_{t}^{o}(z)} W_{t}(z) N_{t}(z)-\frac{N_{t}^{1+\varphi}(z)}{1+\varphi}\right]
$$

subject to a labor demand schedule

$$
N_{t}(z)=\left(\frac{W_{t}(z)}{W_{t}}\right)^{-\epsilon_{w}} N_{t}
$$

Since consumption will generally differ between the two types of consumers, the union weighs labor income with their respective marginal utility of consumption (i.e. $\frac{1}{C_{t}^{r}}$ and $\left.\frac{1}{C_{t}^{o}}\right)$. Notice that, in writing down the problem above, we have assumed that the union takes into account the fact that firms allocate labor demand uniformly across different workers of type $z$, independently of their household type. It follows that, in the aggregate, we will have $N_{t}^{r}=N_{t}^{o}=N_{t}$ for all $t$.

The first order condition of this problem can be written as follows (after invoking symmetry, and thus dropping the $z$ index)

$$
\left(\frac{\lambda}{M R S_{t}^{r}}+\frac{1-\lambda}{M R S_{t}^{o}}\right) W_{t}=\mu^{w}
$$

where $M R S_{t}^{r} \equiv C_{t}^{r} N_{t}^{\varphi}, M R S_{t}^{o} \equiv C_{t}^{o} N_{t}^{\varphi}$, and $\mu^{w} \equiv \frac{\epsilon_{w}}{\epsilon_{w}-1}$.

Log-linearizing expression (40) and ignoring constant terms yields the wage schedule

$$
\begin{aligned}
w_{t} & =\chi_{r} m r s_{t}^{r}+\chi_{o} m r s_{t}^{o} \\
& =\widetilde{c}_{t}+\varphi\left(\chi_{r}+\chi_{o}\right) n_{t}
\end{aligned}
$$

where $\chi_{r} \equiv \frac{\lambda W}{M R S^{r} \mu^{w}}, \chi_{o} \equiv \frac{(1-\lambda) W}{M R S^{o} \mu^{w}}$, and $\widetilde{c}_{t} \equiv \chi_{r} c_{t}^{r}+\chi_{o} c_{t}^{o}$.

Notice that, to the extent that tax policy equates steady state consumption across household types (i.e. $C^{r}=C^{o}$ ) we will have $M R S^{r}=M R S^{o}$ and, hence, $\chi_{r}=\lambda$ and 
$\chi_{o}=1-\lambda$. We can then rewrite the previous equilibrium condition as

$$
w_{t} \equiv c_{t}+\varphi n_{t}
$$

which corresponds to the equation (30) in the text.

Under the present scenario we assume that the wage markup $\mu^{w}$ is sufficiently large (and the shocks sufficiently small) so that the conditions $W_{t}>M R S_{t}^{j}$ for $j=r, o$ are satisfied for all $t$. Both conditions guarantee that both type of households will be willing to meet firms' labor demand at the prevailing wage. 


\section{Appendix 2. Steady State Analysis}

In this short appendix we show that the steady state ratio of aggregate consumption to total output does not depend upon the fraction of rule-of-thumb consumers. In doing so, we just notice that the market clearing condition for final goods implies:

$$
\begin{aligned}
\gamma_{c} & =1-\frac{I}{Y}-\frac{G}{Y} \\
& =1-\frac{\delta \alpha}{\alpha\left(\frac{Y}{K}\right)}-\gamma_{g} \\
& =\left(1-\gamma_{g}\right)-\frac{\delta \alpha}{(\rho+\delta) \mu^{p}}
\end{aligned}
$$

where the last equality follows from the fact that in the steady state $R^{k}=\frac{\alpha}{\mu^{p}} \frac{Y}{K}$ (implied by the constant marginal cost) and $R^{k}=(\rho+\delta)$ (implied by a constant $Q$ ). Notice that this share of consumption on total output it is independent of the share of rule-of-thumb consumers and our assumption on the labor market structure. 


\section{Appendix 3. Derivation of the Reduced Dynamical System}

The equilibrium conditions describing the model dynamics are given by expressions (30)-(37). Now we reduce those conditions to the five variable system (38) in terms of hours, consumption, inflation, capital and government spending.

The first equation in the system (38) corresponds to the linearized capital accumulation equation (25), with $i_{t}$ substituted out using market clearing condition (36) and replacing $y_{t}$ subsequently using the production function (35):

$$
k_{t+1}=\left(1-\delta+\frac{\delta \alpha}{1-\widetilde{\gamma}_{c}}\right) k_{t}+\frac{\delta(1-\alpha)}{1-\widetilde{\gamma}_{c}} n_{t}-\frac{\delta \gamma_{c}}{1-\widetilde{\gamma}_{c}} c_{t}-\frac{\delta}{1-\widetilde{\gamma}_{c}} g_{t}
$$

where $\widetilde{\gamma}_{c}=\gamma_{c}+\gamma_{g}$. In order to derive the second equation in (38) we start by rewriting the inflation equation (32) in terms of variables contained in $\mathbf{x}_{t}$. Using (33) and (30) we obtain an expression for the marginal cost as a function of the consumption output ratio and aggregate hours

$$
\mu_{t}=y_{t}-c_{t}-(1+\varphi) n_{t}
$$

Substituting the previous expression (42) into (32), and making use of (35) yields the second equation in (38)

$$
\begin{aligned}
\pi_{t} & =\beta E_{t}\left\{\pi_{t+1}\right\}+\lambda_{p}\left[c_{t}-y_{t}+(1+\varphi) n_{t}\right] \\
& =\beta E_{t}\left\{\pi_{t+1}\right\}+\lambda_{p} c_{t}-\alpha \lambda_{p} k_{t}+(\alpha+\varphi) \lambda_{p} n_{t}
\end{aligned}
$$

\section{Aggregate Euler Equation: the Case of Perfectly Competitive Labor}

Markets As noticed above, under the assumption of perfectly competitive labor markets, we can log-linearize expressions (8), (12), and combine them with (28) and (29) to yield expression (30). From log-linearizing expression (12) we obtain an expression for the evolution of the hours worked by the rule-of-thumb consumers 


$$
n_{t}^{r}=\varphi^{-1}\left(w_{t}-c_{t}^{r}\right)
$$

We now substitute the previous expression as well as (30) into expression (27). After rearranging terms this yields $c_{t}^{r}$ as a function only of aggregate variables,

$$
\left[\mu^{p} \gamma_{c} \varphi+(1-\alpha)\right] c_{t}^{r}=(1-\alpha)(1+\varphi) c_{t}+(1-\alpha)(1+\varphi) \varphi n_{t}-\mu^{p} \varphi t_{t}^{r}
$$

As before noticed, we also apply the operator $\left(1-L^{-1}\right)$ to expression $(28)$, which yields

$$
c_{t}-E_{t}\left\{c_{t+1}\right\}=\lambda\left[c_{t}^{r}-E_{t}\left\{c_{t+1}^{r}\right\}\right]+(1-\lambda)\left[c_{t}^{o}-E_{t}\left\{c_{t+1}^{o}\right\}\right]
$$

Finally, we substitute expressions (44) and (26) into the previous one, which after rearranging terms, yields the Euler equation for aggregate consumption presented in the main text

$$
c_{t}=E_{t}\left\{c_{t+1}\right\}-\frac{1}{\widetilde{\sigma}}\left(r_{t}-E_{t}\left\{\pi_{t+1}\right\}\right)-\Theta_{n} E_{t}\left\{\Delta n_{t+1}\right\}+\Theta_{\tau} E_{t}\left\{\Delta t_{t+1}^{r}\right\}
$$

where $\frac{1}{\widetilde{\sigma}} \equiv(1-\lambda) \Gamma\left[\mu^{p} \varphi \gamma_{c}+(1-\alpha)\right], \Theta_{n} \equiv \lambda \Gamma(1-\alpha)(1+\varphi) \varphi, \Theta_{t} \equiv \lambda \Gamma \mu^{p} \varphi$, and $\Gamma \equiv \frac{1}{\gamma_{c} \mu^{p} \varphi+(1-\alpha)(1-\lambda(1+\varphi))}$.

\section{Aggregate Euler Equation: the Case of Imperfectly Competitive Labor}

Markets We first substitute expression (30) into expression (27), this yields

$$
\begin{aligned}
c_{t}^{r} & =\left(\frac{W N}{C}\right)\left[c_{t}+(1+\varphi) n_{t}\right]-\left(\frac{Y}{C}\right) t_{t}^{r} \\
& =\frac{(1-\alpha)}{\mu^{p} \gamma_{c}} c_{t}+\frac{(1-\alpha)(1+\varphi)}{\mu^{p} \gamma_{c}} n_{t}-\frac{1}{\gamma_{c}} t_{t}^{r}
\end{aligned}
$$

We proceed to use the operator $\left(1-L^{-1}\right)$ into the previous expression yielding

$$
\begin{aligned}
c_{t}^{r}-E_{t}\left\{c_{t+1}^{r}\right\}= & \frac{(1-\alpha)}{\gamma_{c} \mu^{p}}\left[c_{t}-E_{t}\left\{c_{t+1}\right\}\right]+ \\
& \frac{(1-\alpha)(1+\varphi)}{\gamma_{c} \mu^{p}}\left[n_{t}-E_{t}\left\{n_{t+1}\right\}\right]-\frac{1}{\gamma_{c}}\left[t_{t}^{r}-E_{t}\left\{t_{t+1}^{r}\right\}\right]
\end{aligned}
$$


We also apply the operator $\left(1-L^{-1}\right)$ to expression $(28)$, which yields

$$
c_{t}-E_{t}\left\{c_{t+1}\right\}=\lambda\left[c_{t}^{r}-E_{t}\left\{c_{t+1}^{r}\right\}\right]+(1-\lambda)\left[c_{t}^{o}-E_{t}\left\{c_{t+1}^{o}\right\}\right]
$$

Finally, we substitute expressions (45) and (26) into the previous one, which after rearranging terms yields an Euler-like equation for aggregate consumption:

$$
\begin{aligned}
c_{t}= & E_{t}\left\{c_{t+1}\right\}-\frac{\gamma_{c} \mu^{p}(1-\lambda)}{\gamma_{c} \mu^{p}-\lambda(1-\alpha)}\left(r_{t}-E_{t}\left\{\pi_{t+1}\right\}\right) \\
& -\frac{\lambda(1+\varphi)(1-\alpha)}{\gamma_{c} \mu^{p}-\lambda(1-\alpha)} E_{t}\left\{\Delta n_{t+1}\right\} \\
& +\frac{\lambda \mu^{p}}{\gamma_{c} \mu^{p}-\lambda(1-\alpha)} E_{t}\left\{\Delta t_{t+1}^{r}\right\}
\end{aligned}
$$

or, more compactly,

$$
c_{t}=E_{t}\left\{c_{t+1}\right\}-\frac{1}{\widetilde{\sigma}}\left(r_{t}-E_{t}\left\{\pi_{t+1}\right\}\right)-\Theta_{n} E_{t}\left\{\Delta n_{t+1}\right\}+\Theta_{t} E_{t}\left\{\Delta t_{t+1}^{r}\right\}
$$

where $\frac{1}{\widetilde{\sigma}} \equiv \gamma_{c} \Phi(1-\lambda) \mu^{p}, \Theta_{n} \equiv \lambda \Phi(1-\alpha)(1+\varphi), \Theta_{t} \equiv \lambda \Phi \mu^{p}$, and $\Phi \equiv \frac{1}{\gamma_{c} \mu^{p}-\lambda(1-\alpha)}$, which are the coefficients of this expression in the text.

Plugging into the Euler equation the interest rate rule (18), the fiscal rule (20), and using the fact the government spending follows a first order autoregressive process (21) we obtain the third equation in (38):

$$
\begin{aligned}
c_{t}-\Theta_{n} n_{t}+\frac{\phi_{\pi}}{\widetilde{\sigma}} \pi_{t}= & E_{t}\left\{c_{t+1}\right\}+\frac{1}{\widetilde{\sigma}} E_{t}\left\{\pi_{t+1}\right\}-\Theta_{n} E_{t}\left\{n_{t+1}\right\} \\
& +\Theta_{t} \phi_{b} \Delta b_{t+1}+\Theta_{t} \phi_{g}\left(\rho_{g}-1\right) g_{t}
\end{aligned}
$$

In order to derive the fourth equation we first combine (42) and (34) to obtain $r_{t}^{k}=c_{t}-k_{t}+(1+\varphi) n_{t}$. The latter expression and the interest rate rule (18), allows us to rewrite the equations describing the dynamics of Tobin's $q$ and investment as follows:

$$
\begin{aligned}
i_{t}-k_{t}= & \beta E_{t}\left\{\left(i_{t+1}-k_{t+1}\right)\right\} \\
& +\eta[1-\beta(1-\delta)]\left[E_{t}\left\{c_{t+1}\right\}-k_{t+1}+(1+\varphi) E_{t}\left\{n_{t+1}\right\}\right] \\
& -\eta \phi_{\pi} \pi_{t}+\eta E_{t}\left\{\pi_{t+1}\right\}
\end{aligned}
$$


Finally, substituting the relationship

$$
i_{t}-k_{t}=\left(\frac{1}{1-\widetilde{\gamma}_{c}}\right)\left[(1-\alpha) n_{t}-\gamma_{c} c_{t}-g_{t}-\left(1-\widetilde{\gamma}_{c}-\alpha\right) k_{t}\right]
$$

(which can be derived by combining the goods market clearing condition with the production function) into the previous equation and rearranging terms we obtain the fourth equation of our dynamical system

$$
\begin{aligned}
(1-\alpha) n_{t}-\gamma_{c} c_{t}-\left(1-\widetilde{\gamma}_{c}-\alpha\right) k_{t}+\left(1-\widetilde{\gamma}_{c}\right) \eta \phi_{\pi} \pi_{t}= & {[\omega(1+\varphi)+\beta(1-\alpha)] E_{t}\left\{n_{t+1}\right\} } \\
& +\left(\omega-\beta \gamma_{c}\right) E_{t}\left\{c_{t+1}\right\} \\
& -\left[\omega+\beta\left(1-\widetilde{\gamma}_{c}-\alpha\right)\right] k_{t+1} \\
& +\left(1-\widetilde{\gamma}_{c}\right) \eta E_{t}\left\{\pi_{t+1}\right\} \\
& +\left(1-\beta \rho_{g}\right) g_{t}
\end{aligned}
$$

where $\omega \equiv \eta[1-\beta(1-\delta)]\left(1-\widetilde{\gamma}_{c}\right)>0$.

The last two equations of the system correspond to expression (37) describing the debt accumulation and the autoregressive process for government spending (21).

Hence the system of equations (41), (43), (46), (47), (37), and (21) can be written in a matrix form as follows

$$
\text { A } E_{t}\left\{\mathbf{x}_{t+1}\right\}=\mathrm{B} \mathbf{x}_{t}+\varepsilon_{t}
$$

where $\mathbf{x}_{t} \equiv\left[n_{t}, c_{t}, \pi_{t}, k_{t}, b_{t}, g_{t-1}\right]^{\prime}$, and

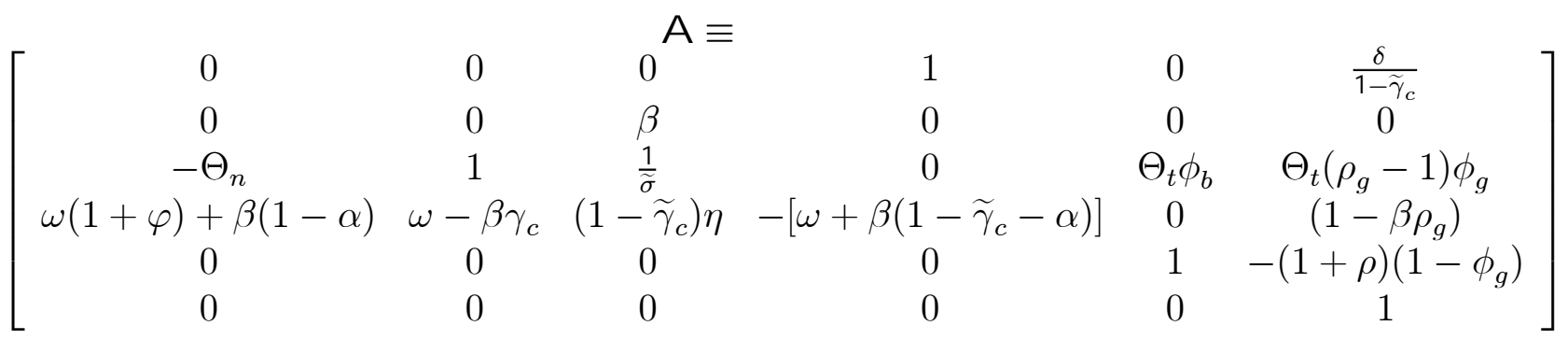




$$
\mathbf{B} \equiv\left[\begin{array}{cccccc}
\frac{\delta(1-\alpha)}{1-\tilde{\gamma}_{c}} & -\frac{\delta \gamma_{c}}{1-\widetilde{\gamma}_{c}} & 0 & 1-\delta+\frac{\delta \alpha}{1-\widetilde{\gamma}_{c}} & 0 & 0 \\
-(\alpha+\varphi) \lambda_{p} & -\lambda_{p} & 1 & \alpha \lambda_{p} & 0 & 0 \\
-\Theta_{n} & 1 & \frac{\phi_{\pi}}{\widetilde{\sigma}} & 0 & \Theta_{t} \phi_{b} & 0 \\
1-\alpha & -\gamma_{c} & \left(1-\widetilde{\gamma}_{c}\right) \eta \phi_{\pi} & \widetilde{\gamma}_{c}+\alpha-1 & 0 & 0 \\
0 & 0 & 0 & 0 & (1+\rho)\left(1-\phi_{b}\right) & 0 \\
0 & 0 & 0 & 0 & 0 & \rho_{g}
\end{array}\right]
$$




\section{References}

Aiyagari, Rao, Lawrence Christiano and Martin Eichenbaum (1990): "Output, Employment and Interest Rate Effects of Government Consumption", J ournal of Monetary E conomics, 30, 73-86.

Alesina, Alberto, Silvia Ardagna, Roberto Perotti and Fabio Schiantarelli (2002): "Fiscal Policy, Profits, and Investment," American E conomic Review, 92 (3), 571-589.

Alesina, Alberto and Silvia Ardagna, (1998): "Tales of Fiscal Adjustment", E conomic Policy, No. 27, October 1998, pp. 489-545.

Amato, Jeffery D., and Thomas Laubach (2003): "Rule-of-Thumb Behavior and Monetary Policy," European Economic Review , vol. 47, 5, pages 791-831

Basu, Susanto, and Miles Kimball (2003): "Investment Planning Costs and the Effects of Monetary and Fiscal Policy," University of Michigan, mimeo.

Baxter, Marianne and Robert King (1993): "Fiscal Policy in General Equilibrium", American Economic Review, 83, 315-334.

Bilbiie, Florin O. (2005): "Limited Asset Market Participation, Monetary Policy, and Inverted Keynesian Logic," mimeo, Nuffield College, Oxford U.

Bilbiie, Florin O. and Roland Straub (2005): "Fiscal Policy, Business Cycles and Labor Market Fluctuations," European University Institute, mimeo.

Bilbiie, Florin O., André Maier, and Gernot J. Müller (2005): "Asset Market Participation, Monetary Policy, and the Effects of U.S. Government Spending: What Accounts for the Declining Fiscal Mulitplier?," Goethe University, Frankfurt, mimeo.

Campbell, John Y. and N. Gregory Mankiw (1989): "Consumption, Income, and Interest Rates: Reinterpreting the Time Series Evidence," in O.J. Blanchard and S. Fischer (eds.), NBER Macroeconomics Annual 1989, 185-216, MIT Press.

Clarida, Richard, Jordi Galí, and Mark Gertler (2000): "Monetary Policy Rules and Macroeconomic Stability: Evidence and Some Theory," Quarterly J ournal of Economics, vol. CXV, issue 1, 147-180.

Christiano, Lawrence and Martin Eichenbaum (1992): "Current Real Business 
Cycles Theories and Aggregate Labor Market Fluctuations", American Economic Review, 82, 430-450.

Blanchard, Olivier (2003): Macroeconomics, Third Edition, Prentice Hall

Blanchard, Olivier and Roberto Perotti (2002): "An Empirical Characterization of the Dynamic Effects of Changes in Government Spending and Taxes on Output," Quarterly J ournal of E conomics,117, 4, 1329-1368.

Bohn, Henning (1998): "The Behavior of Public Debt and Deficits", T he Quarterly J ournal of Economics 113(3), 949-964.

Burnside, Craig, Martin Eichenbaum and Jonas Fisher (2003): "Fiscal Shocks and their Consequences", NBER WP 9772.

Campbell, John Y. and N. Gregory Mankiw (1989): "Consumption, Income, and Interest Rates: Reinterpreting the Time Series Evidence," in O.J. Blanchard and S. Fischer (eds.), NBER Macroeconomics Annual 1989, 185-216, MIT Press

Calvo, Guillermo (1983): "Staggered Prices in a Utility Maximizing Framework", J ournal of Monetary E conomics, 12, 383-398.

Clarida, Richard, Jordi Galí and Mark Gertler (1999): " The Science of Monetary Policy: A New Keynesian Perspective", J ournal of Economic Literature, 37, 16611707.

Coenen, G. and R. Straub (2004): "Non-Ricardian Households and Fiscal Policy in an Estimated DSGE Model of the Euro Area," mimeo.

Deaton, A. (1992), Understanding Consumption, Clarendon Lectures in Economics, Clarendon Press, Oxford, 1992.

Dotsey, Michael (1999): "Structure from Shocks," Federal Reserve Bank of Richmond Working Paper 99-6.

Dupor, Bill (2002): "Interest Rate Policy and Investment with Adjustment Costs," mimeo.

Edelberg, Wendy, Martin Eichenbaum, and Jonas Fisher (1999), "Understanding the Effects of Shocks to Government Purchases," Review of Economic Dynamics, 2, 
166-206.

Erceg, C.J., Guerrieri, L. and Gust, C. J., (2005): "SIGMA A New Open Economy Model for Policy Analysis," Federal Reserve Board, International Finance Discussion Papers, no. 835 .

Erceg, C.J., Guerrieri, L. and Gust, C. J., (2005): "Expansionary Fiscal Shocks and the Trade Deficit", FRB International Finance Discussion Paper No. 825.

Fatás, Antonio and Ilian Mihov (2001): "The Effects of Fiscal Policy on Consumption and Employment: Theory and Evidence," INSEAD, mimeo.

Galí, Jordi, J.David López-Salido and Javier Vallés (2004): "Rule-of- Thumb Consumers and the Design of Interest Rate Rules", J ournal of Money, Credit and Banking, Vol. 36 (4), August 2004, 739-764.

Giavazzi, Francesco, and Marco Pagano (1990): "Can Severe Fiscal Contractions be Expansionary? Tales of Two Small European Countries" in O.J. Blanchard and S. Fischer (eds.), NBER Macroeconomics Annual 1990, MIT Press

Hemming, Richard, Michael Kell and Selma Mahfouz (2002): "The effectiveness of Fiscal Policy in Stimulating Economic Activity-A Review of the Literature," IMF WP $02 / 208$

IMF (2004), W orld Economic Outlook, 2004, IMF Washington D.C. April 2004.

Johnson, D; J. Parker, and N. Souleles (2004): "Household Expenditure and the Income Tax Rebates of 2001", NBER Working Paper 10784, September 2004.

Kim, Jinill (2000): "Constructing and estimating a realistic optimizing model of monetary policy," J ournal of Monetary Economics, 45, 2, 329-359

King, Robert, and Mark Watson (1996): "Money, Prices, Interest Rates and the Business Cycle" Review of Economics and Statistics, 78, 35-53

Mankiw, N. Gregory (2000): "The Savers-Spenders Theory of Fiscal Policy," American Economic Review, 90, 2, 120-125.

Mountford, Andrew and Harald Uhlig (2000): "What are the Effects of Fiscal Policy Shocks?, mimeo, Humboldt University, Berlin, june 2004. 
Perotti, Roberto (1999): "Fiscal Policy in Good Times and Bad," Quarterly J ournal of Economics, 114, 4, 1399-1436.

Perotti, Roberto (2004): "Estimating the Effects of Fiscal Policy in OECD Countries, IGIER, March 2004.

Ramey, Valerie, and Matthew Shapiro (1998): "Costly Capital Reallocation and the Effect of Government Spending," Carnegie-Rochester C onference Series on P ublic Policy, 48, 145-194.

Rotemberg, Julio and Michael Woodford (1992): "Oligopolistic Pricing and the Effects of Aggregate Demand on Economic Activity", J ournal of Political Economy, 100, 1153-1297.

Rotemberg, Julio and Michael Woodford (1995): "Dynamic General Equilibrium Models with Imperfectly Competitive Products Markets", in Thomas F. Cooley (ed.), Frontiers in Business Cycle Research, Princeton University Press.

Rotemberg, Julio and Michael Woodford (1997): "An Optimization Econometric Framework for the Evaluation of Monetary Policy" in O.J. Blanchard and S. Fischer (eds.), NBER Macroeconomics Annual 1997, MIT Press.

Rotemberg, Julio and Michael Woodford (1999):" Interest Rate Rules in an Estimated Sticky Price Model" in J.B. Taylor (ed.), Monetary Policy Rules, University of Chicago Press and NBER.

Taylor, John B. (1993): "Discretion versus Policy Rules in Practice," Carnegie Rochester Conference Series on Public Policy , December 1993, 39, 195-214.

Wolff, Edward (1998): "Recent Trends in the Size Distribution of Household Wealth", J ournal of E conomic Perspectives 12, 131-150.

Woodford, Michael (2003) Interest and Prices, Chapter 4, Princeton University Press.

Yun, Tack (1996): "Nominal Price Rigidity, Money Supply Endogeneity, and Business Cycles," J ournal of M onetary E conomics 37, 345-370. 
Table 1. Estimated Effects of Government Spending Shocks

\begin{tabular}{|c|c|c|c|c|c|c|c|c|c|}
\hline & \multicolumn{6}{|c|}{ Estimated Fiscal Multipliers } & \multicolumn{3}{|c|}{$\overline{\text { Implied }}$} \\
\hline & \multicolumn{3}{|c|}{ Output } & \multicolumn{3}{|c|}{ Consumption } & \multicolumn{3}{|c|}{ Fiscal Parameters } \\
\hline & 1 stQ & 4 thQ & 8 thQ & 1 stQ & 4 thQ & 8thQ & $\rho_{g}$ & $\phi_{g}$ & $\phi_{b}$ \\
\hline & \multicolumn{6}{|c|}{ 1948:I-2003:IV } & & & \\
\hline \multicolumn{10}{|l|}{ Baseline Spending } \\
\hline Small VAR & 0.51 & 0.31 & 0.28 & 0.04 & 0.09 & 0.19 & 0.85 & 0.10 & 0.10 \\
\hline Larger VAR & 0.41 & 0.31 & 0.68 & 0.07 & 0.11 & 0.49 & 0.80 & 0.06 & 0.06 \\
\hline \multicolumn{10}{|l|}{ Excluding Military } \\
\hline Small VAR & 0.15 & -0.12 & 0.34 & -0.11 & 0.24 & 0.32 & 0.95 & 0.005 & 0.60 \\
\hline Larger VAR & 0.36 & 0.62 & 1.53 & 0.03 & 0.51 & 0.68 & 0.94 & 0.005 & 0.60 \\
\hline \multicolumn{10}{|c|}{ 1954:I-2003:IV } \\
\hline Baseline Spending & & & & & & & & & \\
\hline Small VAR & 0.74 & 0.75 & 1.22 & 0.14 & 0.46 & 0.73 & 0.95 & 0.13 & 0.20 \\
\hline Larger VAR & 0.68 & 0.70 & 1.74 & 0.17 & 0.29 & 0.95 & 0.95 & 0.10 & 0.30 \\
\hline \multicolumn{10}{|l|}{ Excluding Military } \\
\hline Small VAR & 0.63 & 1.95 & 2.60 & 0.25 & 1.41 & 1.12 & 0.95 & 0.05 & 0.50 \\
\hline Larger VAR & 0.74 & 2.37 & 3.50 & 0.37 & 1.39 & 1.76 & 0.95 & 0.01 & 0.50 \\
\hline \multicolumn{10}{|c|}{ 1960:I-2003:IV } \\
\hline Baseline Spending & & & & & & & & & \\
\hline Small VAR & 0.91 & 1.05 & 1.32 & 0.19 & 0.59 & 0.84 & 0.95 & 0.13 & 0.20 \\
\hline Larger VAR & 0.81 & 0.44 & 0.76 & 0.20 & 0.25 & 0.45 & 0.95 & 0.08 & 0.20 \\
\hline \multicolumn{10}{|l|}{ Excluding Military } \\
\hline Small VAR & 0.72 & 1.14 & 1.19 & 0.17 & 0.78 & 0.68 & 0.94 & 0.03 & 0.50 \\
\hline Larger VAR & 1.13 & 1.89 & 2.08 & 0.40 & 1.14 & 1.07 & 0.98 & 0.01 & 0.55 \\
\hline
\end{tabular}

Note: The "large" VAR corresponds to the 8-variable VAR described in the text; the "small" VAR estimates are based on a 4-variable VAR including government spending, output, consumption, and the deficit. Government spending excluding military was obtained as GFNEH+GSEH+GFNIH+GSIH. For each specification $\rho_{g}$ is the $\operatorname{AR}(1)$ coefficient that matches the half-life of the estimated government spending response. Parameter $\phi_{g}$ is obtained as the difference of the VAR-estimated impact effects of government spending and deficit, respectively. Finally, given $\rho_{g}$ and $\phi_{g}$, we calibrate the parameter $\phi_{b}$ such that the dynamics of government spending (21) and debt (37) are consistent with the horizon at which the deficit is back to steady state, matching our empirical VAR responses of the fiscal deficit. 


\section{Figure 1}

\section{The Dynamic Effects of a Government Spending Shock}
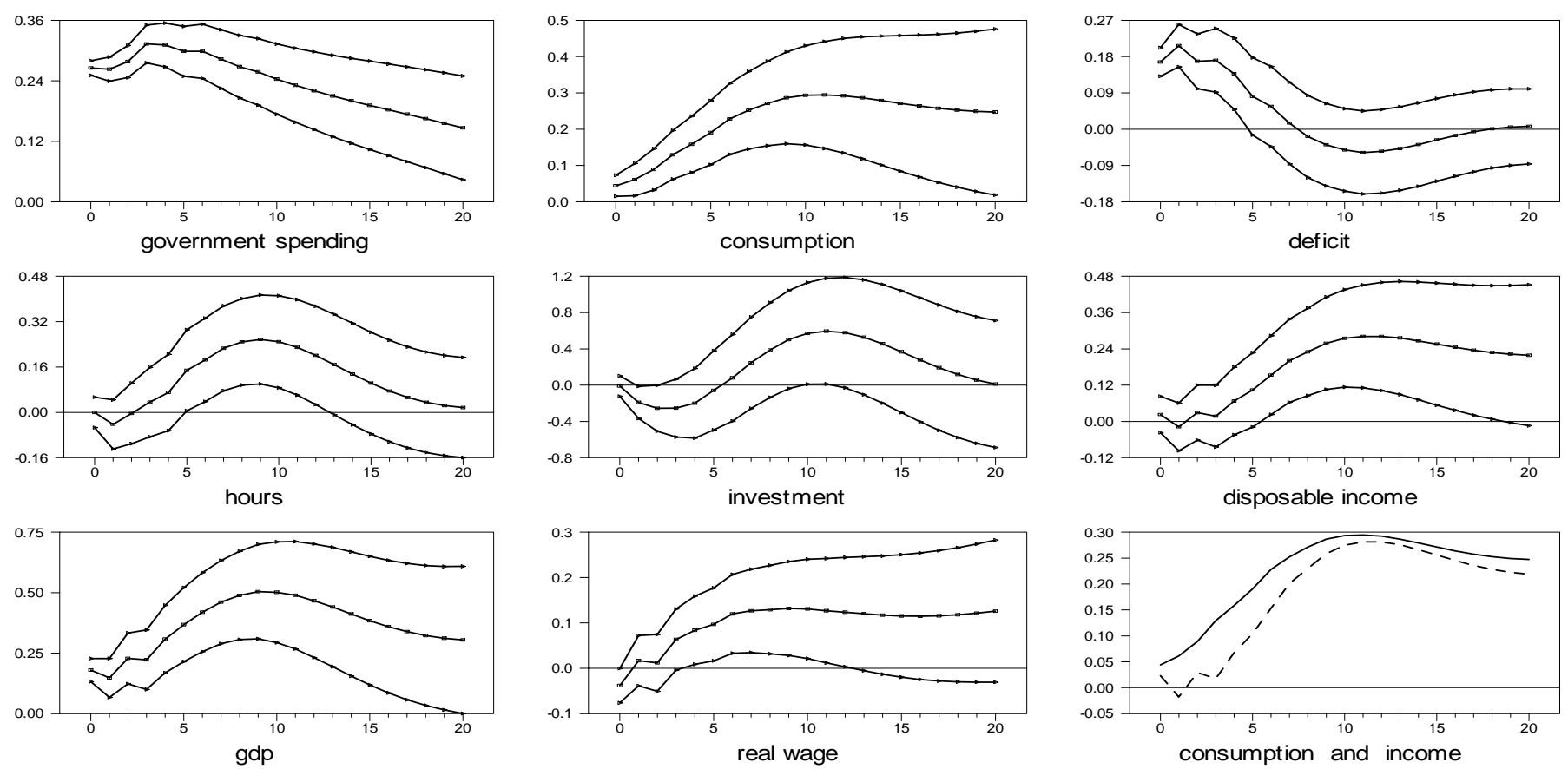

Note: Estimated impulse responses to a government spending shock in the large VAR. Sample Period 1954:I-2003:IV. The horizontal axis represents quarters after the shock. Confidence intervals correspond +/- 1 standard deviations of empirical distributions, based on 1000 Monte Carlo replications. The right bottom panel plots the point estimates of both consumption (solid line) and disposable income (dashed line) 


\section{Figure 2. Determinacy Analysis}

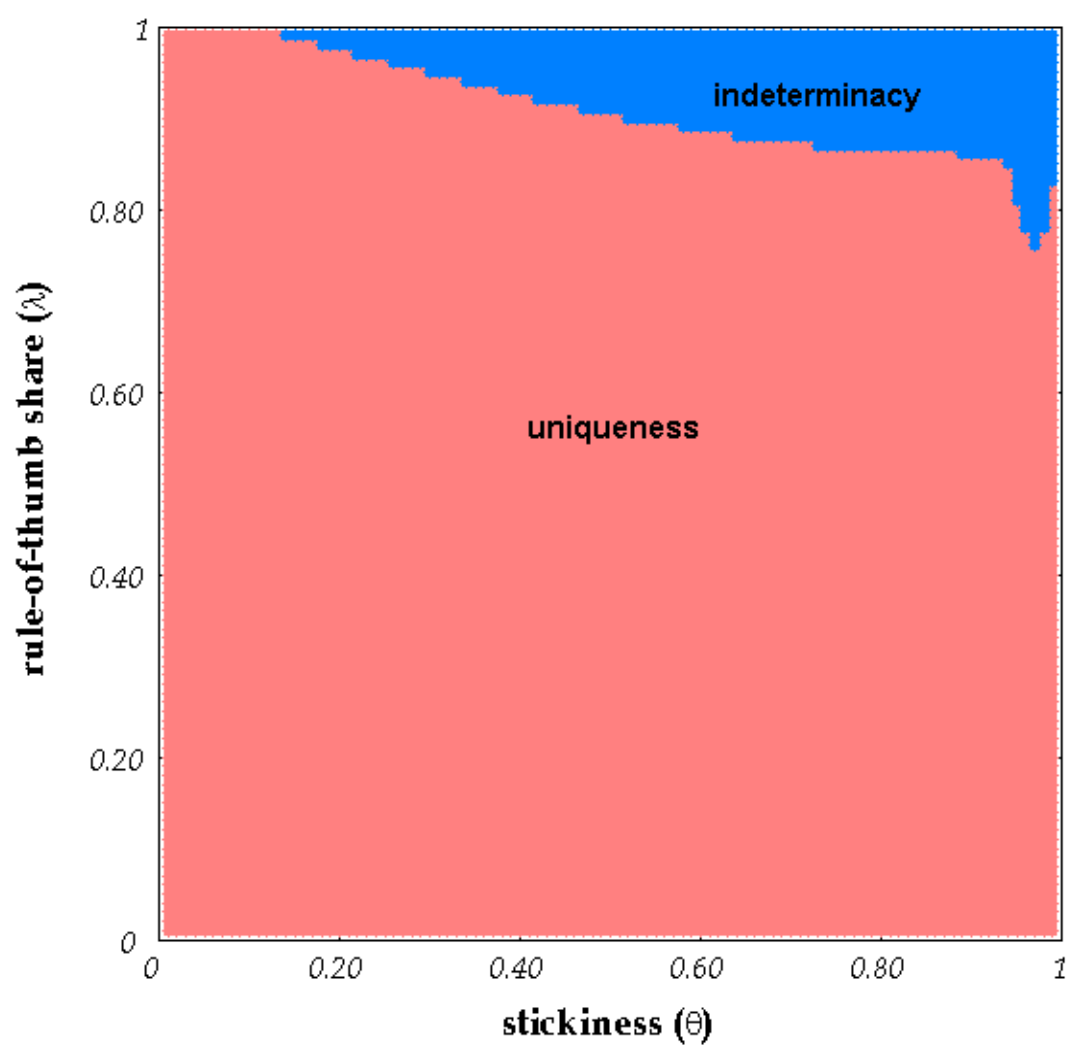

Note: Based on the model with competitive labor markets, remaining parameters at their baseline values. 


\section{Figure 3. Impact Multipliers: Sensitivity to $\lambda$}

A. Competitive Labor Market

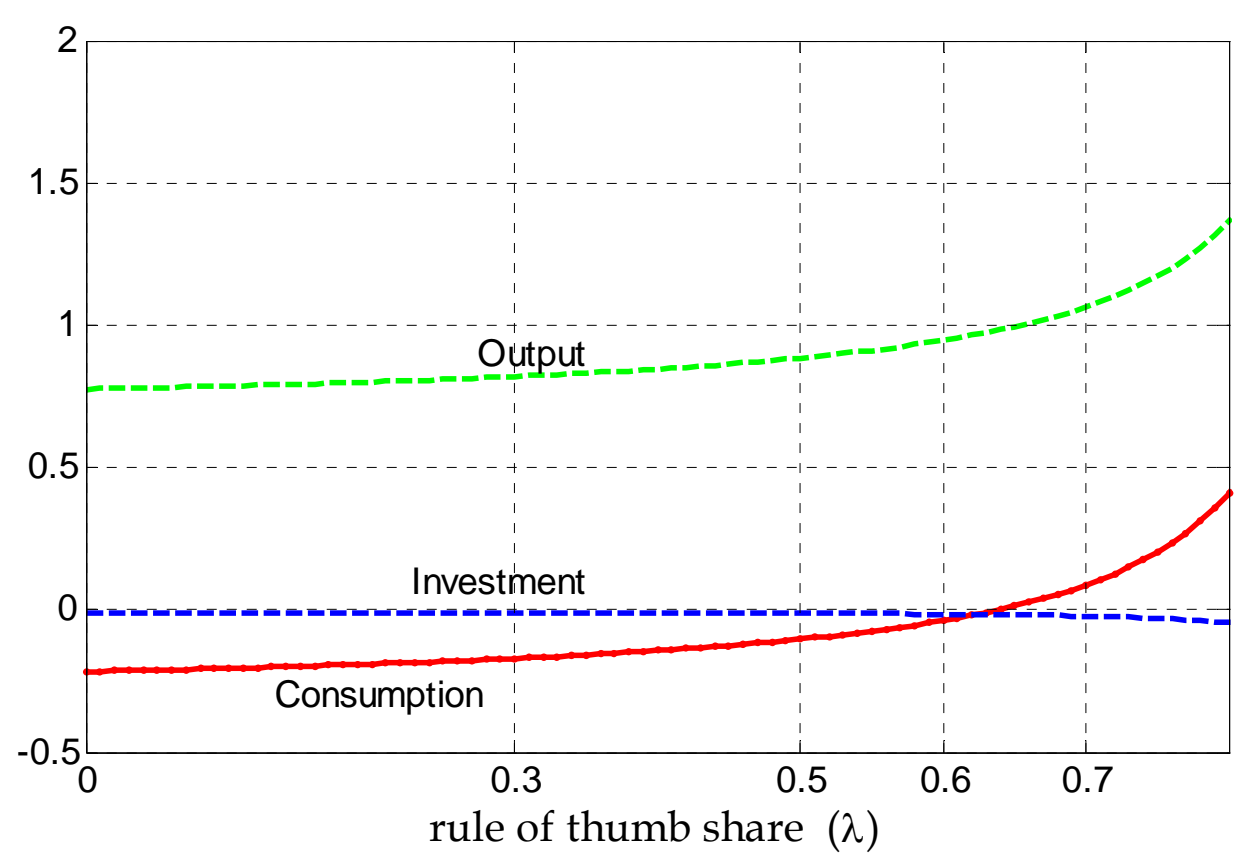

B. Non-Competitive Labor Market

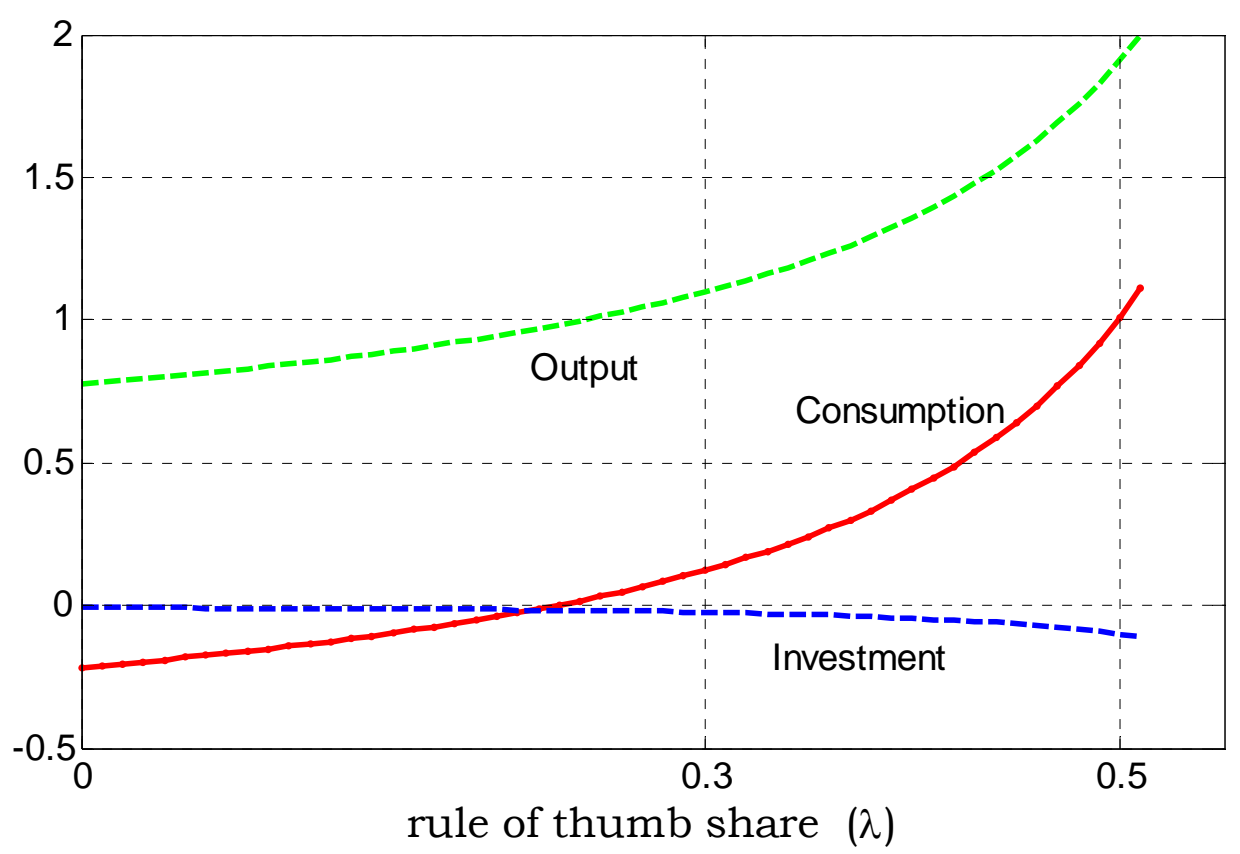

Note: Baseline calibration for remaining parameters. 
Figure 4. The Dynamic Effects of a Government Spending Shock: Baseline vs. Neoclassical Models

A. Competitive Labor Market
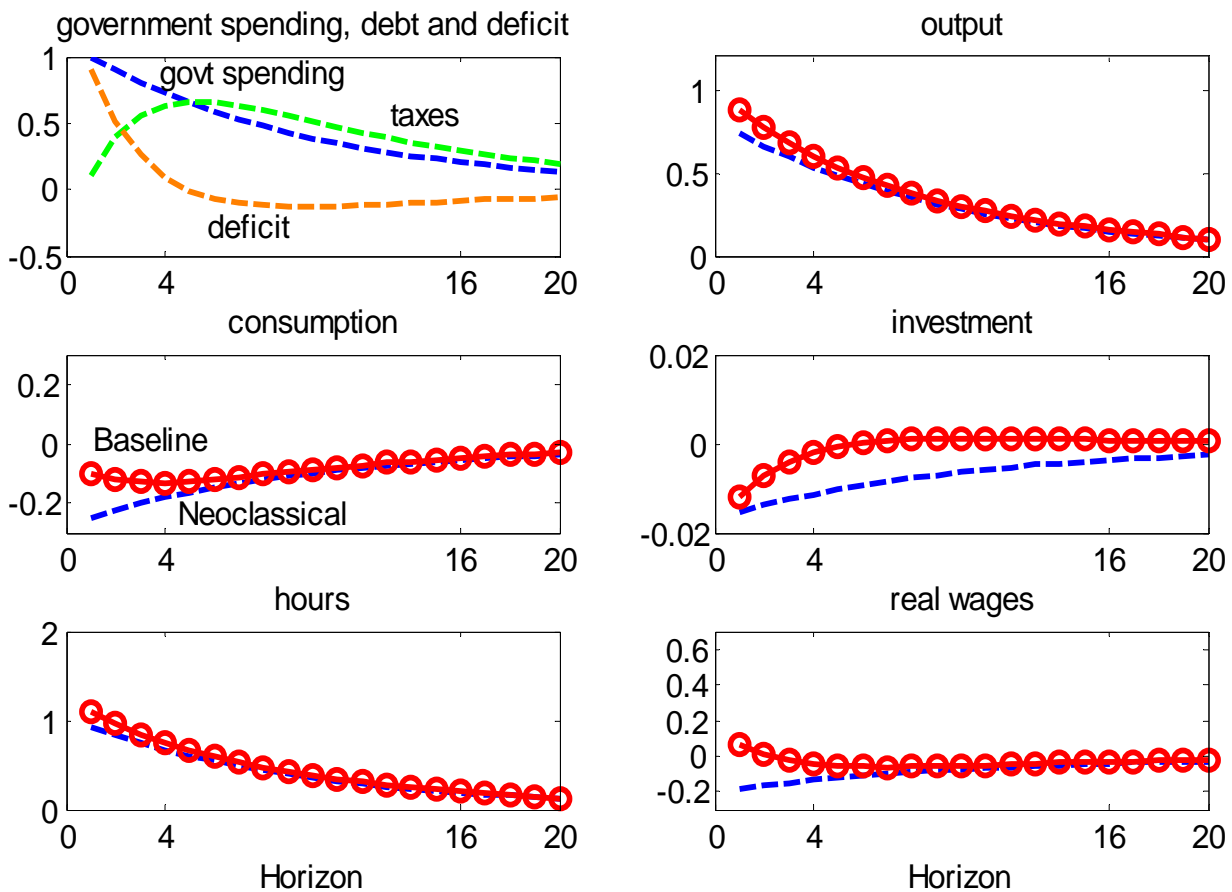

B. Non-Competitive Labor Market
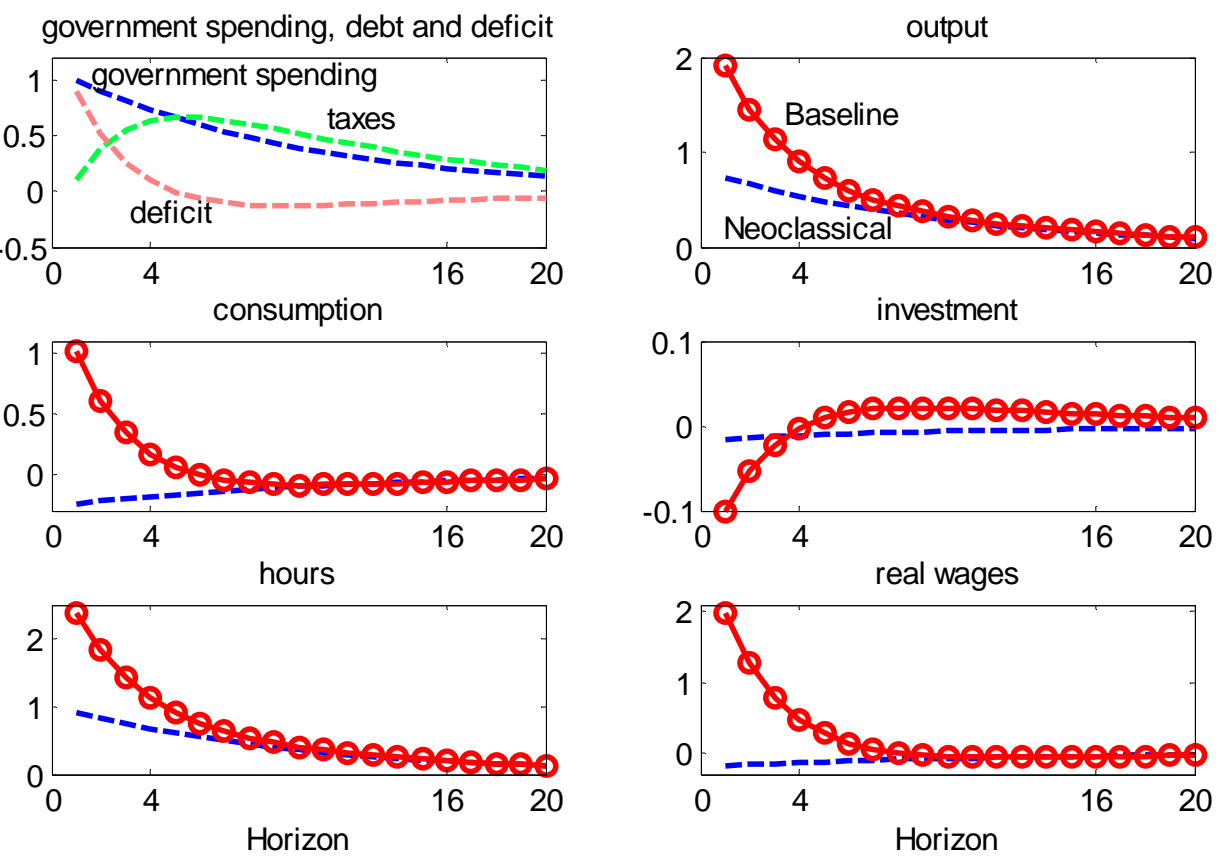

Note: Baseline calibration (circles), neoclassical calibration (dashes). 
Figure 5. Impact Multipliers: Sensitivity to $\rho_{\mathrm{g}}$ Alternative Calibrations (Non Competitive Labor Market)
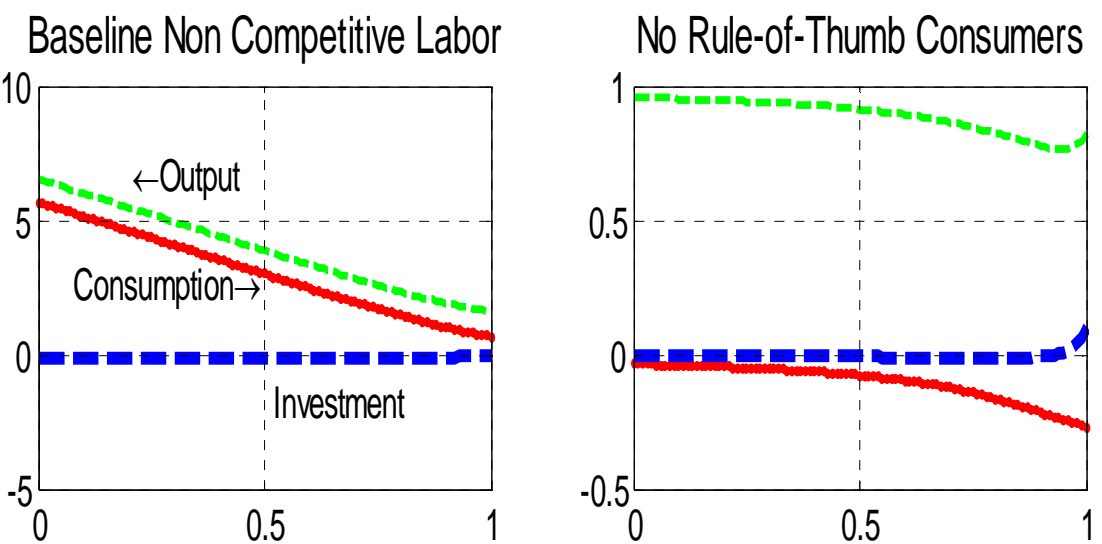

Flexible Prices

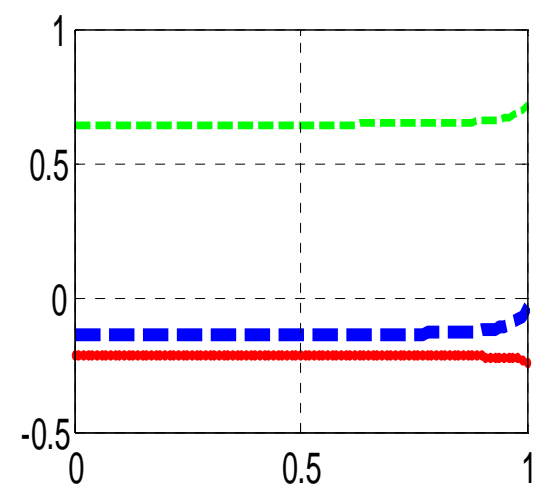

Neoclassical

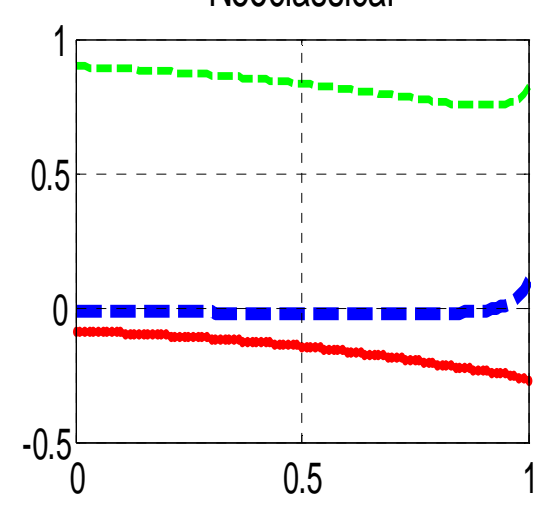

Persistence of Gov Spending Shock ( $\left.\rho_{n}\right)$ 
Figure 6. Impact Multipliers:

Sensitivity to Non-Policy Parameters $(\theta, \varphi, \eta)$
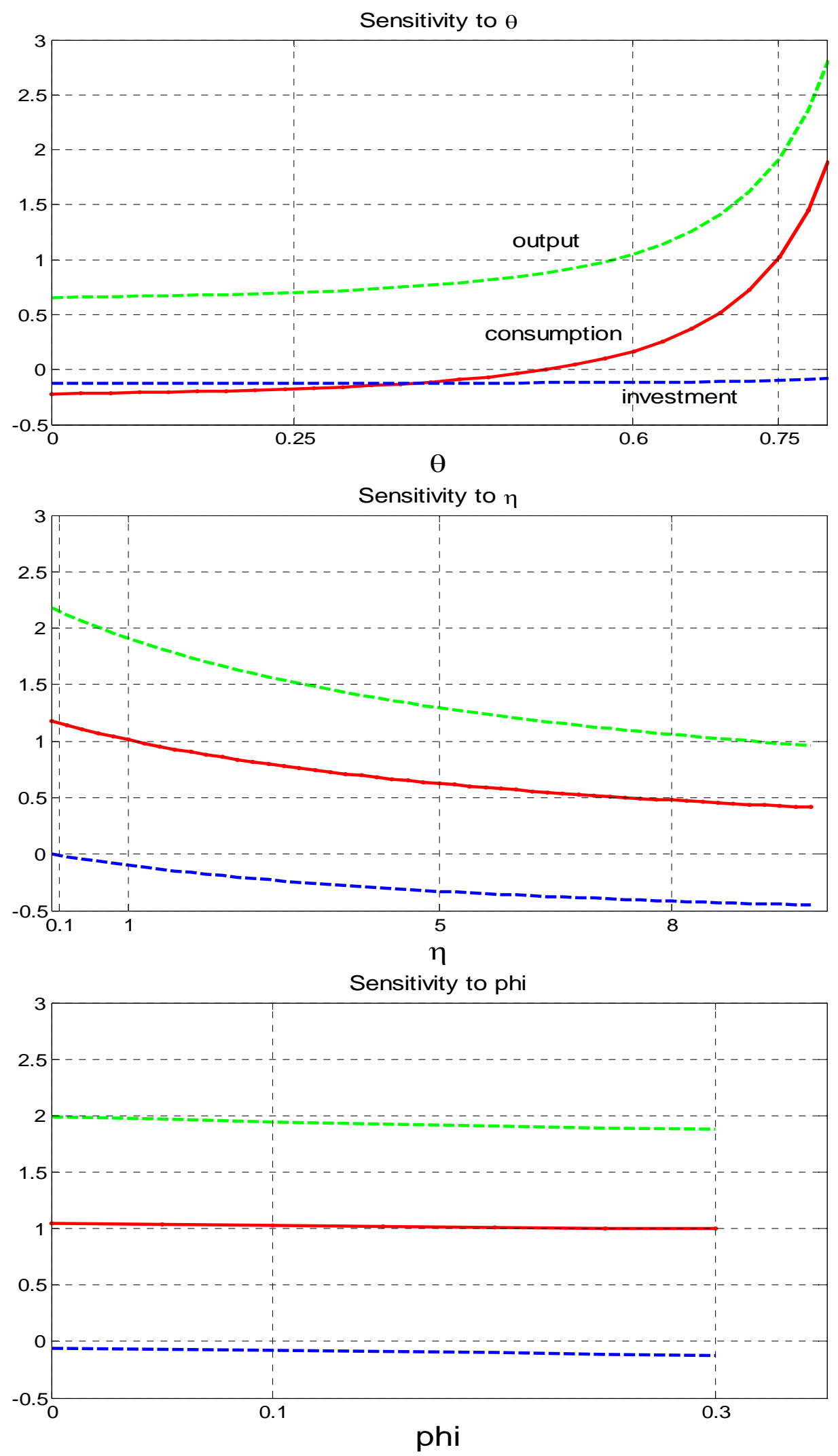
Figure 7. Impact Multipliers:

Sensitivity to Policy Parameters $\left(\phi_{\pi}, \phi_{\mathrm{g}}, \phi_{\mathrm{b}}\right)$
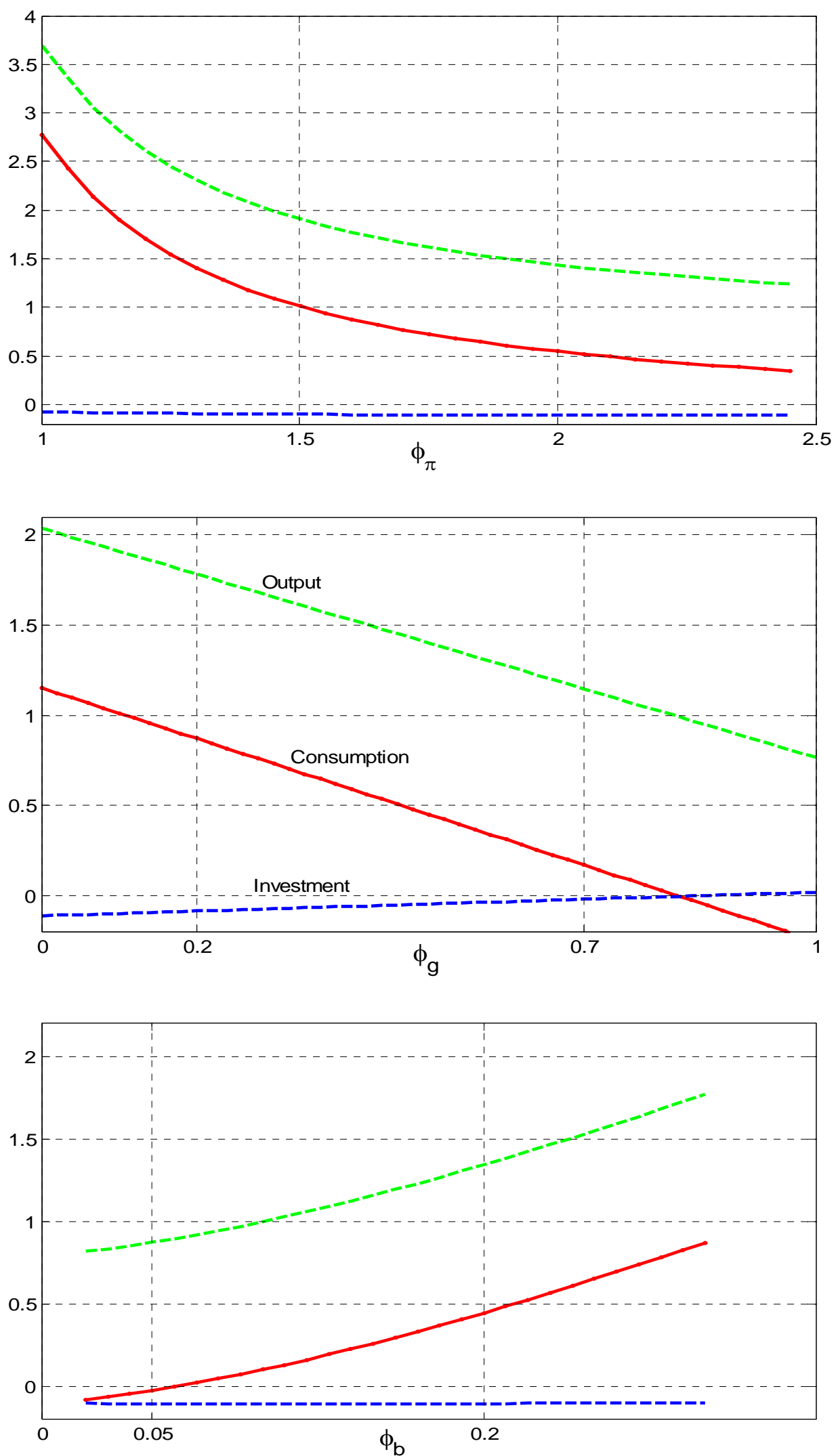